Published in final edited form as:

J Phys Chem B. 2019 February 21; 123(7): 1578-1591. doi:10.1021/acs.jpcb.8b11982.

\title{
Hole Hopping Across a Protein-Protein Interface
}

\author{
Kana Takematsua ${ }^{a}$ Petr Pospíšil ${ }^{b}$, Martin Pižl $^{b, c}$, Michael Towrie $^{d}$, Jan Heyda ${ }^{b, c}$, Stanislav \\ Záliš $^{b}$, Jens T. Kaisere, Jay R. Winklere, ${ }^{,}$, Harry B. Graye, ${ }^{,}$, and Antonín Vlček ${ }^{b, f,{ }^{*}}$ \\ aDepartment of Chemistry, Bowdoin College, Brunswick, ME 04011, USA \\ bJ. Heyrovský Institute of Physical Chemistry, Academy of Sciences of the Czech Republic, \\ Dolejškova 3, CZ-182 23 Prague, Czech Republic \\ cUniversity of Chemistry and Technology, Prague, Technická 5, CZ-166 28 Prague, Czech \\ Republic \\ ${ }^{d}$ Central Laser Facility, Research Complex at Harwell, Science and Technology Facilities Council, \\ Rutherford Appleton Laboratory, Harwell Oxford, Didcot, Oxfordshire, OX11 OFA, UK \\ eBeckman Institute, California Institute of Technology, Pasadena, CA 91125, USA \\ fQueen Mary University of London, School of Biological and Chemical Sciences, Mile End Road, \\ London E1 4NS, United Kingdom
}

\section{Abstract}

We have investigated photoinduced hole hopping in a Pseudomonas aeruginosa azurin mutant Re126WWCu${ }^{I}$, where two adjacent tryptophan residues (W124 and W122) are inserted between the $\mathrm{Cu}^{\mathrm{I}}$ center and a Re photosensitizer coordinated to a H126 imidazole $\left(\operatorname{Re}=\operatorname{Re}^{\mathrm{I}}(\mathrm{H} 126)\right.$ $(\mathrm{CO})_{3}(\mathrm{dmp})^{+}, \mathrm{dmp}=4,7$-dimethyl-1,10-phenanthroline). Optical excitation of this mutant in aqueous media ( $\$ 40 \mu \mathrm{M}$ ) triggers $70 \mathrm{~ns}$ electron transport over $23 \AA$, yielding a long-lived (120 $\mu \mathrm{s}) \operatorname{Re}^{\mathrm{I}}(\mathrm{H} 126)(\mathrm{CO})_{3}\left(\mathrm{dmp}^{--}\right) \mathrm{WWCu}{ }^{\mathrm{II}}$ product. The $\mathbf{R e 1 2 6 F W C \mathbf { u } ^ { I }}$ mutant $(\mathrm{F} 124, \mathrm{~W} 122)$ is not redox-active under these conditions. Upon increasing the concentration to $0.2-2 \mathrm{mM}$,

$\left\{\operatorname{Re126WWCu}^{\mathbf{I}}\right\}_{\mathbf{2}}$ and $\left\{\operatorname{Re126FWCu}^{\mathbf{I}}\right\}_{\mathbf{2}}$ are formed with the dmp ligand of the Re photooxidant of one molecule in close contact (3.8 $⿱$ $)$ with the W122' indole on the neighboring chain. In

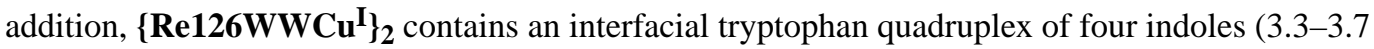
$\AA$ Apart). In both mutants, dimerization opens an intermolecular W122 $\rightarrow / / * \operatorname{Re}$ ET channel (// denotes the protein interface, $* \operatorname{Re}$ is the optically excited sensitizer). Excited-state relaxation and ET occur together in two steps (time constants of $\sim 600 \mathrm{ps}$ and $\sim 8 \mathrm{~ns}$ ) that lead to a chargeseparated state containing a $\operatorname{Re}(\mathrm{H} 126)(\mathrm{CO})_{3}\left(\mathrm{dmp}^{\bullet-}\right) / /\left(\mathrm{W} 122^{\circ+}\right)^{\prime}$ ' unit; then, $\left(\mathrm{Cu}^{\mathrm{I}}\right)^{\prime}$ ' is oxidized intramolecularly (60-90 ns) by (W122*+)', forming $\operatorname{Re}^{\mathrm{I}}(\mathrm{H} 126)(\mathrm{CO})_{3}\left(\mathrm{dmp}^{\bullet-}\right) \mathrm{WWCu} / /\left(\mathrm{Cu}^{\mathrm{II}}\right)^{\prime}$. The photocycle is closed by $\sim 1.6 \mu \operatorname{Re}^{\mathrm{I}}(\mathrm{H} 126)(\mathrm{CO})_{3}\left(\mathrm{dmp}^{--}\right) \rightarrow / /\left(\mathrm{Cu}^{\mathrm{II}}\right)^{\prime}$ back ET that occurs over 12

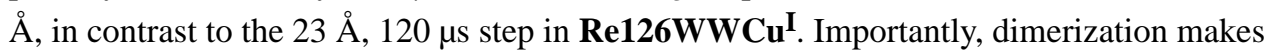

\footnotetext{
*Corresponding Authors: winklerj@caltech.edu, hbgray@caltech.edu, avlcek@qmul.ac.uk. Supporting Information

The Supporting Information is available free of charge on the ACS Publications website at DOI.... Interfacial experimental and calculated azurin stuctures, intramolecular cofactor distances, concentration- and wavelength dependent luminescence decay kinetics, TRIR spectra, reaction scheme for Re126WWCu $\mathbf{I}$.

The authors declare no competing financial interest
} 
Re126FWCu${ }^{I}$ photoreactive and, as in the case of $\left\{\operatorname{Re126WWCu}{ }^{I}\right\}_{2}$, channels the photoproduced "hole" to the molecule that was not initially photoexcited, thereby shortening the lifetime of $\operatorname{Re}^{\mathrm{I}}(\mathrm{H} 126)(\mathrm{CO})_{3}\left(\mathrm{dmp}^{--}\right) / / \mathrm{Cu}^{\mathrm{II}}$. Whereas two adjacent W124 and W122 indoles dramatically enhance $\mathrm{Cu}^{\mathrm{I}} \rightarrow *$ Re intramolecular multistep ET, the tryptophan quadruplex in $\left\{\operatorname{Re126WWCu} \mathbf{u}_{\mathbf{2}}\right.$ does not accelerate intermolecular electron transport; instead, it acts as a hole storage and crossover unit between inter- and intramolecular ET pathways. Irradiation of $\left\{\mathbf{R e 1 2 6 W W C u} \mathbf{u}^{\mathbf{I I}}\right\}_{\mathbf{2}}$ or $\left\{\operatorname{Re126FWCu} \mathbf{u}^{\mathrm{II}}\right\}_{\mathbf{2}}$ also triggers intermolecular W122' $\rightarrow / / * \operatorname{Re} \mathrm{ET}$; and the $\operatorname{Re}(\mathrm{H} 126)$ $(\mathrm{CO})_{3}\left(\mathrm{dmp}^{\bullet-}\right) / /\left(\mathrm{W} 122^{*+}\right)^{\prime}$ charge-separated state decays to the ground state by $\sim 50 \mathrm{~ns} \operatorname{Re}^{\mathrm{I}}(\mathrm{H} 126)$ $(\mathrm{CO})_{3}\left(\mathrm{dmp}^{\bullet-}\right)^{+} \rightarrow / /\left(\mathrm{W} 122^{\bullet+}\right)^{\prime}$ intermolecular charge recombination. Our findings shed light on the factors that control interfacial hole/electron hopping in protein complexes and on the role of aromatic amino acids in accelerating long-range electron transport.

\section{Graphical Abstract}

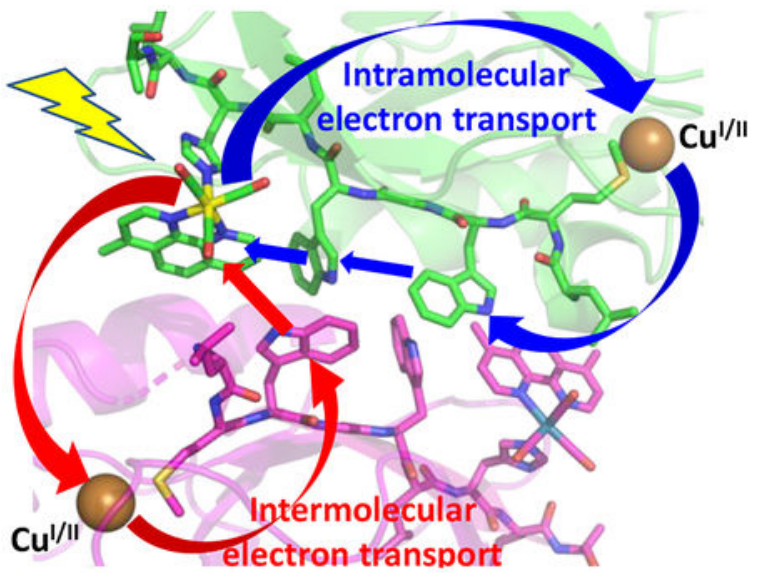

\section{INTRODUCTION}

Pseudomonas aeruginosa azurin, a blue copper protein, provides an excellent platform for investigations of electron transfer (ET) in natural systems. Kinetics studies of $\mathrm{Cu}^{\mathrm{I}}$ oxidation by appended $\mathrm{Ru}$ - or Re-based photosensitizers and of $\mathrm{Cu}^{\mathrm{II}}$ reduction by pulse-radiolytically generated cysteine radical anions established ET pathways and timetables, $1,2,3,4,5,6,7,8,9,10$ while complementary theoretical work provided insights into the nature of tunneling pathways and protein dynamics effects, ${ }^{11,12,13,14,15}$ and, more recently, conformational gating. 16

Introducing one or more tryptophan residues into high-potential ET pathways dramatically accelerates ET and extends its range by changing the mechanism from single-step to multistep tunneling (hopping, $\mathrm{ET}_{\text {hop }}$ ) involving tryptophan radical-cation intermediates. 1,17,18,19 Rapid (50-70 ns) Cu ${ }^{\mathrm{I}}$ photooxidation over 19.4 and $22.9 \AA$ A has been demonstrated in Re-labeled azurin mutants containing one $\mathrm{e}^{20}$ and two ${ }^{21}$ intervening tryptophans. An analogous hopping mechanism was found to accelerate ET across an azurinazurin dimer interface where the Re sensitizer and the tryptophan are in two different molecules. ${ }^{22}$ In addition, ET in azurins also can be accelerated by hopping through nitrotyrosines in redox pathways. ${ }^{23}$ These observations support the hypothesis that long-range ET through 
tryptophan/tyrosine chains is operational in high-potential enzymatic catalysis, either in substrate transformations ${ }^{24,25}$ or offering protection from oxidative damage. ${ }^{17,24,26,27}$

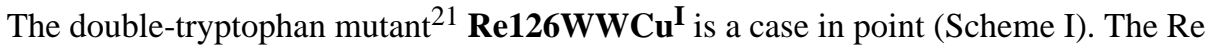
photooxidant $\operatorname{Re}^{\mathrm{I}}(\mathrm{CO})_{3}(\mathrm{dmp})^{+}$(dmp = 4,7-dimethyl-1,10-phenanthroline) was covalently appended through the imidazole side chain of histidine $\mathrm{H} 126$ in an azurin mutant containing two redox-active tryptophans (W124, W122) in the protein; and the naturally occurring W48 and all tyrosines had been replaced by phenylalanines. $\mathrm{Cu}^{\mathrm{I}}$ photooxidation in

Re126WWCuI $\mathbf{I}^{\mathbf{I}}$ is accelerated $\sim 10,000$-fold by hopping through the two intervening typtophans, achieving $70 \mathrm{~ns}$ ET over $22.9 \AA$ (Scheme 1). ${ }^{21}$ The photocycle is completed by $\sim 120 \mu \mathrm{se}^{\mathrm{I}}(\mathrm{H} 126)(\mathrm{CO})_{3}\left(\mathrm{dmp}^{\bullet-}\right) \rightarrow \mathrm{Cu}^{\mathrm{II}}$ back electron transfer (BET), which is not accelerated by hopping, since $\mathrm{Cu}^{\mathrm{II}}$ cannot oxidize tryptophan. The large difference between forward and back ET extends the lifetime of the $\mathrm{Cu}^{\mathrm{II}}$ redox product (RP). Importantly, hopping though a tryptophan chain both accelerates and rectifies phototriggered electron

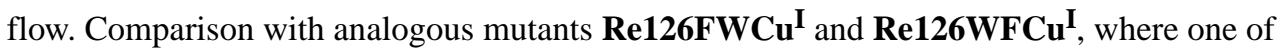
the tryptophans (the first and second letters specify the 124 and 122 residues) is replaced by phenylalanine, has shown ${ }^{21}$ that efficient hopping in this system requires the simultaneous presence of two tryptophans and their close contact with each other, as well as with the adjacent Re photooxidant. Photoinduced ET does not occur in Re126FWCu $\mathbf{u}^{\mathbf{I}}$, whose luminescence decays with the same lifetime $(1.15 \mu \mathrm{s})$ as an isolated *Re chromophore. In Re126WFCu ${ }^{\mathbf{I}}$, *Re emission is quenched by fast ET from neighboring W124, followed by fast charge recombination that regenerates the ground state, without oxidizing $\mathrm{Cu}^{\mathrm{I}} .{ }^{21}$

The Re126WWCuI photocycle and kinetics shown in Scheme 1 were established at low concentrations $\left(\leq 40 \mu \mathrm{M}\right.$ ) in order to minimize dimerization (oligomerization) observed ${ }^{22,28}$ for several azurin mutants and their Re-labeled derivatives. The time constants reported in Scheme 1 are for intramolecular ET in azurin monomers, ${ }^{21}$ while our time-resolved spectroscopic studies revealed multiexponential kinetics with minor components becoming

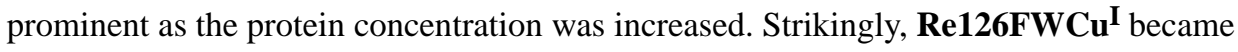
photo-ET active and the contribution of the $120 \mu$ s recombination kinetics of $\operatorname{Re126WWCu} \mathbf{I}^{\mathbf{I}}$ diminished at higher concentrations. Considering the azurin tendency to dimerize, ${ }^{22,28}$ this behavior is attributable to intermolecular ET. Herein, we describe photocycles of $\mathrm{Cu}^{\mathrm{I}}$ and $\mathrm{Cu}^{\mathrm{II}}$ forms of Re126FWCu, Re126WWCu, and Re126WFCu at concentrations $200 \mu \mathrm{M}$ and higher, aiming to shed light on the interplay between intra- and intermolecular electron/ hole hopping.

\section{RESULTS}

Structures.

The X-ray crystal structure of Re126WWCuII (PDB: 6MJS; Figure 1A) ${ }^{21}$ shows multiple short (3.5 - $4.0 \AA$ ) intramolecular contacts between the mutually T-oriented aromatic groups of redox cofactors $\operatorname{Re}(\mathrm{H} 126)(\mathrm{CO})_{3}(\mathrm{dmp})^{+}, \mathrm{W} 124$, and W122 along the $22.9 \AA$

intramolecular Re---Cu ET pathway (see Table $\mathrm{S} 1$ for ET-relevant intramolecular distances).

${ }^{21}$ The W122 indole is separated from the Cu atom by 11 $\AA$; and the structure of the W122Cu pathway is virtually the same as in $\operatorname{Re126FWCu}{ }^{\text {II }},{ }^{21} \operatorname{Re126T124W122Cu}^{\text {II }},{ }^{22}$ and 
Re124W122Cu ${ }^{\text {II }}{ }^{20}$ Molecular structures of Re126WFCu ${ }^{\text {II }}$ (6MJT), Re126FWCuII (6MJR), and $\mathbf{R e 1 2 6 W W C u}{ }^{\text {II }}$ are nearly superimposable. ${ }^{21}$ In $\mathbf{R e 1 2 6 F W C u}{ }^{I I}$, the $\operatorname{Re}$ chromophore is redox-isolated since the W122 residue is too far from the Re site. ${ }^{21}$

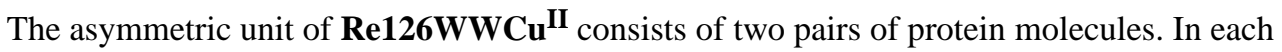
pair, the ET-active regions of the two molecules face each other (Figures 1B, S1A; distances summarized in Table 1). The four mutually T-oriented tryptophan indoles (W124, W122, $\mathrm{W} 124^{\prime}$, and $\mathrm{W} 122^{\prime}$ ), which are closely spaced in the interfacial region, form a tight cage (a tryptophan quadruplex). W124 and W122' indoles on different molecules make several short C-C contacts. In addition, the W124 N-H is in a close (2.3-2.6 $⿱$ A) interaction with the benzene ring of the W122' indole (and, similarly between W122 and W124'). Short indoleindole contacts also occur diagonally across the quadruplex (W124-W124' and W122W122'). Each Re(dmp) unit is in close contact with a nearly parallel W122' indole on the neighbor molecule, as well as with $\mathrm{W} 124$ on the same molecule. The protein-protein interface is hydrophobic (each W122 and W122' indole NH group is H-bonded (2.1-2.3 $\mathrm{A}$ ) to a water molecule lying in the indole plane). The intermolecular dmp-Cu distance is $8.6 \AA$ shorter than the intramolecular one. Molecular packing in the Re126FWCu $\mathbf{u}^{\mathbf{I I}}$ asymmetric unit is very similar: the Re complex lies in a close proximity to the W122' indole of the other molecule and F124 of one chain interacts with W122' of the other (3.6 A, T-oriented, Figure 1C). The molecular interface of $\mathbf{R e 1 2 6 F W C u} \mathbf{I I}^{\mathbf{I}}$ is nearly superimposable with Re126WWCuII (Figure S1B) and similar to Re126TWCu${ }^{\text {II }}$ (Figure S1C). ${ }^{22}$ In the case of Re126WFCuII the two molecules in the asymmetric unit have the regions containing redox cofactors oriented outwards, but facing complementary ET regions of the molecules in neighboring unit cells. Pymol-generated symmetry mates (Figure 1D) show a small-area interface with intermolecular $\pi$-stacking between dmp ligands and a short dmp-W124' intermolecular contact. The interaction between the two Re complexes is similar to that in Re124W122CuII (2I7O, Figure S1D).

In solutions, azurins and their Re-labeled derivatives form dimers whose structures are assumed to be very close to those found crystallographically. ${ }^{22,28}$ This assumption was supported by DFT structure optimization of bare $\left\{\operatorname{Re}(\mathrm{CO})_{3}(\mathrm{dmp}) \mathrm{H} 126 \mathrm{~L} 125 \mathrm{~W} 124 \mathrm{G} 123 \mathrm{~W} 122\right\}_{2}$ in water modeled as dielectric-continuum (Figure S2), as well as by QM/MM optimization of the $\left\{\operatorname{Re126WWCu}^{\mathbf{I}}\right\}_{\mathbf{2}}$ dimer solvated with 2088 explicit water molecules (Figure S3). Both optimization procedures, which were performed without structural constraints, well reproduced the interfacial structure of the crystal, including the interactions and distances between cofactors (Table S2). It follows that the interface is predominantly stabilized by electronic interactions and dispersion between the cofactors.

\section{Photoinduced Electron Transport}

Photocycles of Re126FWCu, Re126WWCu, and Re126WFCu were investigated at concentrations in the $0.2-2 \mathrm{mM}$ range by time-resolved luminescence that reports on the decay kinetics of * Re in the ${ }^{3} \mathrm{CT}$ excited state, and by time-resolved IR spectroscopy (TRIR) that exhibits features ${ }^{29}$ specific for ${ }^{3} \mathrm{CT}\left({ }^{*} \mathrm{Re}\right)$ and reduced $\mathrm{Re}^{\mathrm{I}}(\mathrm{H} 126)(\mathrm{CO})_{3}\left(\mathrm{dmp}^{*-}\right)$ that occurs in CS and RP states. (The ${ }^{3} \mathrm{CT}$, CS, and RP notation is used similarly to Scheme 1.) 
The Re126FWCu photocycle.-This azurin is largely unreactive upon 400 or $355 \mathrm{~nm}$ irradiation at low concentrations ( $\leq 40 \mu \mathrm{M}$ ) since the intramolecular distance between the $\operatorname{Re}(\mathrm{H} 126)(\mathrm{CO})_{3}(\mathrm{dmp})$ and the W122 indole $(7.1 \AA)$ is too long to support excited-state ET, effectively decoupling the Re and Cu centers. ${ }^{21}$ Excitation of the Re label in $\operatorname{Re126FWCu}{ }^{\mathbf{I}}$ at 400 or $355 \mathrm{~nm}$ populates the ${ }^{3} \mathrm{CT}$ state (Scheme 1) whose photoluminescence decays multiexponentially with a principal lifetime of $1.15 \mu \mathrm{s}^{21}$ that shortens to $\sim 300 \mathrm{~ns}$ in the $\mathrm{Cu}^{\mathrm{II}}$ derivative, presumably by energy transfer to lower-lying $\mathrm{Cu}^{\mathrm{II}}$-localized electronic states. The

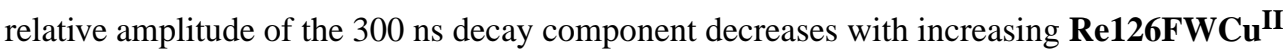
concentration, while shorter-lived kinetics $(5-8, \sim 50 \mathrm{~ns})$ gain in prominence, their amplitudes asymptotically increasing (Figure 2, Table S3). In analogy with Re126TWCuII, 22 we have attributed the short-lived decay kinetics to a photoreactive dimer $\left\{\operatorname{Re126FWCu} \mathbf{u}^{\mathrm{II}}\right\}_{\mathbf{2}}$, where the *Re luminescence is quenched by intermolecular W122, $\rightarrow / / * \operatorname{Re}$ ET (//denotes the protein-protein interface). The concentration dependence of the relative amplitude of the short decay kinetics was analyzed ${ }^{22}$ assuming that a photoreactive dimer is in equilibrium with an unreactive monomer ( $300 \mathrm{~ns}$ lifetime). The estimated

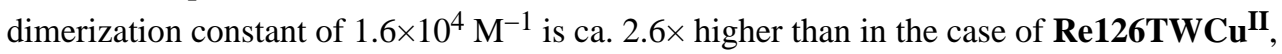
${ }^{22}$ likely due to the presence of a second aromatic residue (F124) at the interface.

In the picosecond domain, 0.3-1.2 $\mathrm{mM} \operatorname{Re126} \mathbf{F W C u} \mathbf{u}^{\text {II }}$ solution luminescence decays with a major $\sim 50$ ps component whose relative amplitude decreases with increasing luminescence wavelength and decreasing concentration (Tables S4, S5). This behavior, which is attributable to a dynamic Stokes shift, reflects relaxation of the *Re site and its environment. 30,31 Minor 540 ns and 5-8 ns decay components are likely related to intermolecular ET

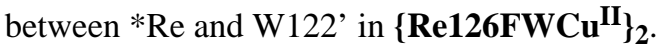

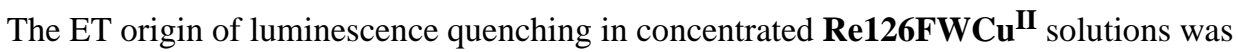
confirmed by TRIR spectra measured in the region of $\mathrm{CO}$ stretching vibrations at time delays ranging from 500 fs to tens of microseconds after 400 or $355 \mathrm{~nm}$ excitation of the Re label. Difference TRIR spectra of $\mathrm{Cu}^{\mathrm{II}}$ and $\mathrm{Cu}^{\mathrm{I}} \mathbf{R e 1 2 6 F W C u}$ (Figure 3) show two negative features due to a bleached ground-state population: a sharp band at $\sim 2028 \mathrm{~cm}^{-1}$ corresponding to the in-phase $A^{\prime}(1)$ vibration and a broad band around $1926 \mathrm{~cm}^{-1}$ originating from quasidegenerate A" and out-of-phase A'(2) vibrations. ${ }^{32}$ (Symmetry labelling assumes $C_{\mathrm{s}}$ local symmetry.) CT excitation shifts all $v(\mathrm{CO})$ bands to higher wavenumbers and lifts the $\mathrm{A}^{\prime \prime} / \mathrm{A}^{\prime}(2)$ quasidegeneracy, ${ }^{29,32,33,34}$ giving rise to three ${ }^{3} \mathrm{CT}$ (*Re) excited-state bands marked $\mathrm{CT}^{\mathrm{a}}, \mathrm{CT}^{\mathrm{b}}$, and $\mathrm{CT}^{\mathrm{c}}$. The bleach and the $\mathrm{CT}$ features emerge together with a weak LCS feature within the experiment time resolution of ca. 500 fs. $\left(\mathrm{CS}\right.$ spectral features are due to reduced $\operatorname{Re}^{\mathrm{I}}(\mathrm{H} 126)(\mathrm{CO})_{3}\left(\mathrm{dmp}^{--}\right)$. They occur at 1885 and $2004 \mathrm{~cm}^{-1}$, abbreviated LCS (Low-CS) and HCS (High-CS), respectively.) The temporal evolution is visualized using evolution- and decay-associated spectra in Figures 4 and 5, obtained by TRIR global kinetics fitting (Table 2). A dynamic shift of the $\mathrm{CT}^{\mathrm{a}}$ band (and, less, of $\mathrm{CT}^{\mathrm{b}}, \mathrm{CT}^{\mathrm{c}}$ ) to higher wavenumbers (attributable ${ }^{30,35}$ to relaxation of the ${ }^{3} \mathrm{CT}$ state) occurs in picosecond and early nanosecond time domains. LCS and HCS increase in intensity and upshift with $\sim 6$ and $\sim 600$ ps time constants, accompanied by upshift and a small decay of the CT features. Nanosecond spectra exhibit strong CS, CT, and bleach features formed within the laser pulse excitation. Early-time spectra also show a shoulder at 
$\sim 1985 \mathrm{~cm}^{-1}$ on the left side of the $2004 \mathrm{~cm}^{-1}$ HCS band. Temporal evolution is dominated by concomitant CT decay and CS rise taking place with $14\left(\mathrm{Cu}^{\mathrm{II}}\right)$ and $6-8 \mathrm{~ns}\left(\mathrm{Cu}^{\mathrm{I}}\right)$ time constants. The $\sim 1985 \mathrm{~cm}^{-1}$ shoulder disappears and LCS shifts from $\sim 1874$ to $\sim 1885 \mathrm{~cm}^{-1}$ concomitantly. For $\mathrm{Cu}^{\mathrm{II}}$, the $\mathrm{CT}, \mathrm{CS}$, and bleach features primarily decay with $\sim 63 \mathrm{~ns}$ kinetics, closing the photocycle. In the $\mathrm{Cu}^{\mathrm{I}}$ form, the related 70-90 ns kinetics involve predominantly the CT decay and bleach recovery, as well as minor CS decay. Principal CS decay is much slower, 1-2 $\mu$ s. Also, the $\operatorname{Re}^{\mathrm{I}}(\mathrm{H} 126)(\mathrm{CO})_{3}\left(\mathrm{dmp}^{\bullet-}\right)$ yield (estimated from the ratio of the LCS and CT band maxima in the nanosecond spectra) is higher in the $\mathrm{Cu}^{\mathrm{I}}$ form. Both the higher CS intensity and longer lifetime indicate that the reduced Re species is stored in long-lived RP. (In addition, a very weak signal persists for both $\mathrm{Cu}^{\mathrm{II}}$ and $\mathrm{Cu}^{\mathrm{I}}$ far into the microsecond range, indicating low-yield formation of a side product containing a reduced Re species, such as a monomer, protein with a deprotonated indole radical W122*, or a dissociated reduced Re complex.)

Re126FWCu photobehavior at high concentrations is attributable to a dimer, $\{\operatorname{Re126FWCu}\}_{2}$, as evidenced by concentration-dependent luminescence decay kinetics (Figure 2) and supported by analogy ${ }^{22}$ with $\left\{\operatorname{Re126TWCu^{I}}\right\}_{2}$. The similar pico- and earlynanosecond TRIR spectra of $\mathrm{Cu}^{\mathrm{II}}$ and $\mathrm{Cu}^{\mathrm{I}}$ species confirm that * Re is reduced by the W122' indole. A proposed reaction mechanism is shown in Scheme 2 . An optically generated ${ }^{1} \mathrm{CT}$ excited state undergoes $\sim 150$ fs intersystem crossing ${ }^{36}$ to a hot ${ }^{3} \mathrm{CT}$ state and a parallel lowyield conversion to CS by sub-picosecond ET from the W122' indole on the neighboring protein molecule. The CS presence in the first $(0.5 \mathrm{ps})$ spectrum indicates that $* \operatorname{Re}$ and the W122' indole are in closer contact than possible in monomers ( $3.5 \AA$ in $\left\{\mathbf{R e 1 2 6 F W C u} \mathbf{u}^{\mathbf{I I}}\right\}_{\mathbf{2}}$, Table 1). CS formation then continues alongside ${ }^{3} \mathrm{CT}$ relaxation with ca. 6 and 600 ps time constants. (The relaxation process at later stages likely involves changing protein solvation and/or conformations around the Re binding site. ${ }^{30}$ ) The (nearly) relaxed ${ }^{3} \mathrm{CT}$ state is in equilibrium with the CS state; and a time constant of $14 / 8-9 \mathrm{~ns}\left(\mathrm{Cu}^{\mathrm{II}} / \mathrm{Cu}^{\mathrm{I}}\right)$ was estimated for W122' $\rightarrow / / *$ Re forward ET. The CS state decays to the ground state by $\operatorname{Re}^{\mathrm{I}}(\mathrm{H} 126)$

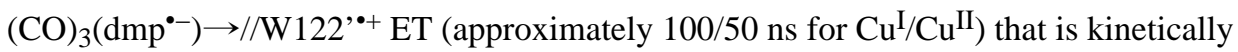
coupled to ${ }^{3} \mathrm{CT}$ decay through equilibrium $K_{1}$. This reaction closes the $\mathrm{Cu}^{\mathrm{II}}$ photocycle. In the $\mathrm{Cu}^{\mathrm{I}}$ form, the $\mathrm{ET}_{\text {hop }}$ process proceeds further by $\sim 50 \mathrm{~ns}\left(\mathrm{Cu}^{\mathrm{I}}\right)^{\prime} \rightarrow\left(\mathrm{W} 122^{\circ+}\right)^{\text {, }}$ intramolecular ET, and the photocycle is completed by $\sim 2 \mu$ intermolecular back ET $\operatorname{Re}^{\mathrm{I}}(\mathrm{H} 126)(\mathrm{CO})_{3}\left(\mathrm{dmp}^{--}\right) \rightarrow / / \mathrm{Cu}^{\mathrm{II}}$. Additionally, TRIR spectra indicate that there are two CS states: the predominant conformation $\left(2004 \mathrm{~cm}^{-1}\right)$ is formed by the kinetics described above, while the minor one (broadening of the low-wavenumber side of LCS and the 1985 $\mathrm{cm}^{-1}$ shoulder) is formed at short picosecond times and within the nanosecond excitation pulse. It decays with early ns kinetics, probably by relaxing to the predominant CS state. (Alternatively, with respect to the mechanism described above, two variants of $\{\operatorname{Re126FWCu}\}_{\mathbf{2}}$ could be present in the solution, one undergoing 10-12 ns W122 $\rightarrow * \operatorname{Re}$ ET (as described above) and the other reacting faster, with a hundreds of picoseconds time constant, owing to tighter (shorter) interactions between the cofactors at the protein-protein interface.)

The Re126WWCu photocycle.-At low concentrations ( $\leq 40 \mu \mathrm{M}$ ), the doubletryptophan mutant undergoes very fast ET (Scheme 1), whereby the *Re luminescence 
decays with lifetimes of about $270 / 290 \mathrm{ps}\left(\mathrm{Cu}^{\mathrm{I}} / \mathrm{Cu}^{\mathrm{II}}\right), 4$, and $80 \mathrm{~ns}$ (both oxidation states). Excitation of the $\mathrm{Cu}^{\mathrm{I}}$ form results in $\sim 68 \mathrm{~ns}$ rise of the $\mathrm{Cu}^{\mathrm{II}}$ absorption at $633 \mathrm{~nm}$, followed by $\sim 120 \mu$ s decay. ${ }^{21}$

The Re126WWCuII luminescence decay in concentrated solutions ( $\geq 200 \mu \mathrm{M}$ ) exhibits $\sim 100$ and 300-450 ps kinetics whose amplitudes are virtually independent of concentration (Table S6). The 100 ps process likely combines *Re quenching with a dynamic Stokes shift ${ }^{31}$ (Table S7) due to *Re relaxation dynamics. The $300-450$ ps lifetime is only a little longer than that measured in diluted solutions. ${ }^{21}$ It is related to *Re quenching by W124 and, presumably, also W122' on the neighboring protein molecule. Nanosecond decay components (Table S8) represent only minor contributions to the overall kinetics. The 4-11 ns lifetime, which is close to that observed for $\left\{\operatorname{Re126FWCu} \mathbf{C u}^{\mathbf{I I}}\right\}_{\mathbf{2}}$ (Table S3), likely results from intermolecular ET. The $66 \mathrm{~ns}$ decay has its counterpart in low-concentration experiments and its amplitude decreases with increasing concentration (Table S8). It is pertinent to the intramolecular CS1 decay $\left(\operatorname{Re}^{\mathrm{I}}(\mathrm{H} 126)(\mathrm{CO})_{3}\left(\mathrm{dmp}^{\bullet-}\right) \rightarrow \mathrm{W} 124^{\circ+}\right)$ and to its intermolecular counterpart CS1' involving (W124 ${ }^{\circ+}$ )' on the other (unexcited) molecule.

TRIR spectra of Re126WWCu measured at 0.6-2 mM concentrations (Figure S4) are qualitatively similar for $\mathrm{Cu}^{\mathrm{I}}$ and $\mathrm{Cu}^{\mathrm{II}}$ but the two states differ in recombination kinetics (Table 3). Their temporal development is demonstrated by evolution- and decay-associated spectra (Figures 6,7 ) xxobtained by TRIR global kinetics fitting. The ground-state bleach, three CT features, and a weak red-shifted LCS band (at $1865 \mathrm{~cm}^{-1}$, accompanied by a $\sim 1985$ HCS shoulder) appear immediately after $50 \mathrm{fs}$ excitation. In the picosecond time domain, all three CT features shift to higher wavenumbers and their intensity slightly decreases. The LCS band grows in intensity and shifts higher. The $1985 \mathrm{~cm}^{-1}$ shoulder diminishes and the $2004 \mathrm{~cm}^{-1}$ HCS band emerges and grows with the $380 / 530$ ps kinetics (demonstrated by decay associated spectra, Figure 7-bottom). Nanosecond experiments show strong LCS and HCS, as well as CT features at the earliest time delays after $355 \mathrm{~nm}, 700 \mathrm{ps}$ excitation. Both CS bands are broadened on their low-energy sides $\left(\sim 1865 \mathrm{~cm}^{-1}\right.$ and a shoulder at $\sim 1985 \mathrm{~cm}$ $\left.{ }^{-1}\right)$. These extra CS shoulders are formed within the $0.7 \mathrm{~ns}$ excitation pulse and decay with a $6.5 / 8.5 \mathrm{~ns}$ lifetime $\left(\mathrm{Cu}^{\mathrm{II}} / \mathrm{Cu}^{\mathrm{I}}\right)$, together with rising $\mathrm{CS}\left(\sim 1880,2004 \mathrm{~cm}^{-1}\right)$ and decaying $\mathrm{CT}$ features. The next $43 / 78$ ns step comprises CS and CT decay. (See Figure S5 for separate 1, 10, and $100 \mathrm{~ns}$ spectra.) Longer-time evolution depends on the copper oxidation state. The $\mathrm{Cu}^{\mathrm{II}}$ photocycle is essentially completed in the $43 \mathrm{~ns}$ step, leaving only a weak long-lived (600-700 ns, $>50 \mu \mathrm{s})$ residual signal. On the other hand, $\mathrm{Cu}^{\mathrm{I}}$ spectra exhibit a stronger $\mathrm{CS}$ signal that decays with major 1.6 and minor $\sim 120 \mu$ s kinetics, accompanied by concomitant bleach recovery. In agreement with TRIR, the transient absorption decay at $633 \mathrm{~nm}$ (attributable to $\mathrm{Cu}^{\mathrm{II}}$ in $\mathrm{RP}^{20,21}$ ) also includes a $\sim 2 \mu$ s component (plus longer decays) when measured in 200 and $250 \mu \mathrm{M}$ solutions, whereas only $\sim 120 \mu$ s decay was found at $\varsigma 40 \mu \mathrm{M}$ for combined 500 and $633 \mathrm{~nm}$ decay. ${ }^{21}$

Spectroscopic and kinetics data obtained for $\mathrm{Cu}^{\mathrm{II}}$ and $\mathrm{Cu}^{\mathrm{I}}$ forms of $\mathrm{Re126WWCu}$ at high concentrations can be explained by a photocycle that assumes parallel intra- and intermolecular $\mathrm{ET}_{\text {hop }}$ processes in $\{\mathbf{R e} 126 \mathrm{WWCu}\}_{2}$. The similarity of picosecond and early nanosecond kinetics measured at low and high concentrations and a very weak concentration dependence of Re126WWCu' ${ }^{\text {II }}$ luminescence decay kinetics suggest that the intra- and 
intermolecular ET steps occur with comparable rates. Acceleration of ground-state recovery from 120 to $1.6 \mu$ s is the main evidence for the occurrence of an intermolecular process. The proposed mechanism is outlined in Scheme 3 and Figure S6: Optical excitation of the Re center produces ${ }^{1} \mathrm{CT}$ that undergoes $\sim 150 \mathrm{fs}^{36}$ intersystem crossing to a hot ${ }^{3} \mathrm{CT}$ state; and low-yield ET from W124/W122' populates the CS1 and/or CS1' states within the first 0.5 ps. Hot ${ }^{3} \mathrm{CT}$ evolves in two relaxation steps $\left(3.5 / 7.1 \mathrm{ps}\right.$ and $380 / 530 \mathrm{ps}$ for $\left.\mathrm{Cu}^{\mathrm{II}} / \mathrm{Cu}^{\mathrm{I}}\right)$ that are coupled with inter- and intramolecular ET from W124 and W122', producing CS1 and CS1', respectively. Notably, ET takes place during vibrational cooling, solvation changes, as well as Re binding site reorganization ${ }^{30}$ (dashed black arrows in Scheme 3). The measured time constants result from convolution of intra- and intermolecular ET with relaxation dynamics. The CS1 (CS1') state is originally hot, characterized by a downshifted LCS feature and the $1985 \mathrm{~cm}^{-1}$ shoulder. The CS relaxation and formation from ${ }^{3} \mathrm{CT}$ proceed with $380 / 530 \mathrm{ps}$ and $6.5 / 8.5 \mathrm{~ns}$ lifetimes $\left(\mathrm{Cu}^{\mathrm{II}} / \mathrm{Cu}^{\mathrm{I}}\right)$. The latter values also are influenced by $\mathrm{CS} 1 / \mathrm{CS} 1{ }^{\prime} \leftrightarrow \mathrm{CS} 2 / \mathrm{CS} 2$ ' conversion kinetics. The next $43 / 80$ ns combined ${ }^{3} \mathrm{CT}+\mathrm{CS}$ decay originates from $\operatorname{Re}^{\mathrm{I}}(\mathrm{H} 126)(\mathrm{CO})_{3}\left(\mathrm{dmp}^{\bullet-}\right) \rightarrow \mathrm{W} 124^{\bullet+} /\left(\mathrm{W} 122^{\circ+}\right)^{\prime}$ recombination in CS1/CS1' states. Intra- and intermolecular charge-separation and recombination $\left(k_{3}, k_{3}{ }^{\prime}\right)$ processes are kinetically coupled through redox equilibria $K_{1}$ and $K_{1}$ '. In addition, the short intermolecular distance ( $3.3 \AA$ ) and the $~ 2.3 \AA \mathrm{NH}$-benzene(indole) H-bond suggest the possibility of intermolecular hole hopping between W124 and W122' residues. The CS1/ CS1' states represents a branching point from which the inter- and intramolecular mechanisms differ. In the intramolecular process, oxidation of W122 to produce CS2 is slightly uphill ( $K_{2}=0.55-0.75 ; 7-9 \mathrm{~ns}$ time constant); it is followed by $60-90 \mathrm{~ns}$ $\mathrm{Cu}^{\mathrm{I}} \rightarrow \mathrm{W} 122^{\bullet+}$ ET and $120 \mu \operatorname{Re}^{\mathrm{I}}(\mathrm{H} 126)(\mathrm{CO})_{3}\left(\mathrm{dmp}^{\bullet-}\right) \rightarrow \mathrm{Cu}^{\mathrm{II}}$ back ET that closes the photocycle (indicated by blue curved arrows in Scheme 3 top-right). ${ }^{21}$ For the intermolecular mechanism, the CS1' formation is followed by intramolecular $\left(\mathrm{Cu}^{\mathrm{I}}\right)^{\prime} \rightarrow$ (W122 ${ }^{\circ+}$ ' ET in the second molecule. A 60-90 ns time constant is assumed, since the ET pathway is virtually the same as in the monomer. On the other hand, $\operatorname{Re}^{\mathrm{I}}(\mathrm{H} 126)$ $(\mathrm{CO})_{3}\left(\mathrm{dmp}^{\cdot-}\right) \rightarrow / /\left(\mathrm{Cu}^{\mathrm{II}}\right)^{\prime}$ back ET is much faster in the dimer $(1.6 \mu \mathrm{s})$ than in the monomer, owing to shorter dmb-Cu distance (see below). Notably, the CS2 and CS2' states play very different roles in intra- and intermolecular $\mathrm{ET}_{\text {hop }}$. Whereas CS2 population involves W122 oxidation and hole transfer along the intramolecular $\mathrm{ET}_{\text {hop }}$ pathway toward $\mathrm{Cu}^{\mathrm{I}}, \mathrm{W} 124$ ' oxidation in CS2' is a side-reaction that is not involved in the $\mathrm{ET}_{\text {hop }}$ process. Still, the $K_{2}$ ' equilibrium could affect the kinetics by storing holes as (W124+*)'. Also, CS2/CS2' states afford another possible crossover between inter- and intramolecular pathways through electron (hole) exchange between the two neighboring tryptophans (double arrow $\mathrm{x} 2$ in Scheme 3 and Figure S6).

The Re126WFCu photocycle.-At low concentrations, the monomer undergoes fast intramolecular W124 photooxidation and a back reaction from CS1 to the ground state. The F122 residue interrupts the intramolecular ET pathway and $\mathrm{Cu}^{\mathrm{I}}$ is not oxidized. Principal *Re luminescence decay lifetimes of ca. 160 ps, $1.6 \mathrm{~ns}$, and 40-80 ns were observed for the $\mathrm{Cu}^{\mathrm{I}}$ form. ${ }^{21}$ Luminescence from a concentrated $(1.8 \mathrm{mM}) \mathbf{R e 1 2 6 W F C u} \mathbf{u}^{\text {II }}$ solution decayed with time constants of 50 and 270 ps (convoluted dynamic Stokes shift and ET quenching), $\sim 4$ and $40 \mathrm{~ns}$ (Table S9). TRIR spectra (Figure S7; evolution- and decay associated spectra in Figures S8, S9) show that the photocycle is very fast for both $\mathrm{Cu}$ oxidation states. CS is 
weakly present in the first spectrum at $0.2 \mathrm{ps}$ and grows with ca. $5,280 \mathrm{ps}\left(\mathrm{Cu}^{\mathrm{II}}\right)$ or $7,450 \mathrm{ps}$ $\left(\mathrm{Cu}^{\mathrm{I}}\right)$ time constants. In nanosecond experiments, a majority of the CS signal emerges during the excitation pulse, including a weak $\sim 1985 \mathrm{~cm}^{-1}$ shoulder that also was seen for the other two azurins. The initial nanosecond spectral evolution $\left(11 / 8 \mathrm{~ns}\right.$ for $\left.\mathrm{Cu}^{\mathrm{II}} / \mathrm{Cu}^{\mathrm{I}}\right)$ is attributable to interfacial $\mathrm{ET}_{\text {hop }}$. It consists of an LCS shift to higher wavenumbers, LCS and HCS intensity growth, LCS narrowing, and decay of CT bands and the $1985 \mathrm{~cm}^{-1}$ shoulder. The photocycle is completed with simultaneous CT and CS decay and bleach recovery that occur with a 40-50 ns time constant for both $\mathrm{Cu}$ oxidation states. The similarity of high- and low-concentration ${ }^{21}$ luminescence decay kinetics, as well as the virtual independence of TRIR decay kinetics on $\mathrm{Cu}$ oxidation state, suggests that the photoreactivity at high concentrations also is mainly limited to the Re/W124/W122' unit (Figure 1). (However, a weak long-lived (> $50 \mu \mathrm{s}$ ) residual LCS/HCS signal was observed for $\mathrm{Cu}^{\mathrm{I}}$, which indicates a low-yield side reaction producing a species containing a reduced Re complex. Hence, partial $\mathrm{Cu}^{\mathrm{I}}$ oxidation in some of the oligomers cannot be excluded.)

\section{DISCUSSION}

Azurin dimerization (oligomerization) at higher concentrations ${ }^{22,28}$ profoundly changes the photobehavior of the Re-labeled protein. Namely, it enables photoinduced electron transport in Re126FWCu ${ }^{I}$ and decreases the RP $\left(\mathrm{Cu}^{\mathrm{II}}\right)$ lifetime in the Re126WWCu${ }^{\mathbf{I}}$ photocycle (from 120 to $1.6 \mu \mathrm{s}$ ). Dimer photoreactivity can be understood assuming that interfacial protein-protein contacts in solution are close to those determined in crystal structures of $\mathrm{Cu}^{\mathrm{II}}$ azurins that was supported by QM/MM structure optimization (Figures 1, S1-S3 and Tables $1, \mathrm{~S} 2)$. In $\left\{\boldsymbol{R e 1 2 6} \mathbf{F W C u} \mathbf{u}^{\mathbf{I I}}\right\}_{\mathbf{2}}$, the pico- and early nanosecond rates of the (W122) $\rightarrow / / * \operatorname{Re}$ step are fully compatible with the short distance $(3.5 \AA)$ and near stacking $\left(23^{\circ}\right)$ between the dmp ligand of the Re label and the W122' indole. Such cofactor arrangement is very similar

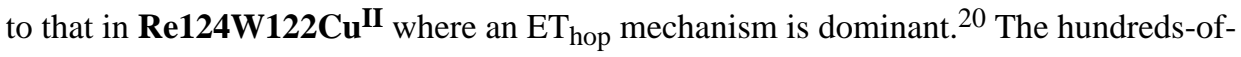
picoseconds and units-of-nanoseconds rates are attributable to ET to *Re in different stages of relaxation and/or to dimers with slightly different interfacial structures. (This behavior was observed for all three investigated azurins, as well as for $^{22}\{\mathbf{R e 1 2 6 T W C u}\}_{2}$.) The $\sim 1.6$ $\mu$ s time constant of $\operatorname{Re}^{\mathrm{I}}(\mathrm{H} 126)(\mathrm{CO})_{3}\left(\mathrm{dmp}^{--}\right) \rightarrow / / \mathrm{Cu}^{\mathrm{II}}$ back ET in $\left\{\operatorname{Re126FWCu}^{\mathbf{I I}}\right\}_{2}$ is compatible with the $12.1 \AA$ dmp-Cu distance. An analogous $3.1 \mu$ s intramolecular step in Re124W122Cu uI $^{\text {II }}$ occurs over $16 \AA .{ }^{20}$ Based only on distances, a time constant of $42 \mathrm{~ns}$ can be estimated for $\left\{\operatorname{Re126FWCu} \mathbf{u}_{\}_{2}}\right.$. However, the intramolecular Cu-dmp ET pathway in $\left\{\text { Re126FWCu} \mathbf{u}^{\mathbf{I I}}\right\}_{2}$ involves a large space jump that would diminish electronic coupling, resulting in $1.6 \mu$ s back ET. Generally, the intermolecular $\mathrm{ET}_{\text {hop }}$ in $\left\{\mathbf{R e 1 2 6 F W C u} \mathbf{C u}_{\mathbf{2}} \mathbf{I}_{\mathbf{2}}\right.$ is similar to that in $\left\{\mathbf{R e 1 2 6 T W C u} \mathbf{u}^{\mathrm{II}}\right\}_{2}{ }^{22}$ The protein-protein interaction in the F124 mutant is stronger due to the presence of two aromatic residues in each molecule.

Both intra- and intermolecular $\mathrm{ET}_{\text {hop }}$ are operational in $\left\{\operatorname{Re126WWCu}_{\mathbf{W}}\right\}_{\mathbf{2}}$; and the intermolecular process is similar to that in $\left\{\operatorname{Re126FWCu} \mathbf{u}^{\mathbf{I}}\right\}_{2}$. The forward and back ET steps follow essentially the same pathways in both azurins and their time constants are comparable within experimental accuracy. Intermolecular (ultra)fast * Re oxidation is enabled by the short (3.8 $⿱$ ) and nearly stacked (11-15 ${ }^{\circ}$ ) arrangement of dmp and W122' cofactors at the interface (Figure 1B, Table 1). The $\left\{\operatorname{Re} 126 \mathbf{W W C u} \mathbf{I I}_{\mathbf{2}}\right\}_{\mathbf{2}}$ structure exhibits an 
interfacial tryptophan quadruplex where the indoles along individual chains and across the interface are separated by 3.9 and $3.3 \AA$, respectively, and an NH-aromatic interaction occurs between W124 and W122', as well as W122 and W124' (Figure 1B). Whereas ET between the two tryptophans ( $K_{2}$ in Schemes 1 and 3 ) is essential for long-range intramolecular hopping, we found no kinetics evidence for its role in intermolecular $\mathrm{ET}_{\mathrm{hop}}$. In fact, oxidation of W124' of the neighboring molecule is a "dead end" that does not facilitate $\mathrm{Cu}^{\mathrm{I}}$ oxidation but could temporarily trap oxidizing equivalents, prolonging the CS1 lifetime but diminishing its population. Moreover, the close proximity of $\mathrm{W}^{\bullet+}$ and $\mathrm{W}$ of the two chains could enable ET between the two protein molecules and, hence, crossovers between intraand intermolecular $\mathrm{ET}_{\text {hop }}$ pathways (marked $\mathrm{x} 1$ and $\mathrm{x} 2$ in Scheme 3). The viability of the tryptophan quadruplex functioning as a "hole storage" or as an ET crossover unit depends on the strength of electronic coupling along and between azurin molecules. The TDDFTcalculated electron-density difference between CS1 and the ground state of solvated $\left\{\operatorname{Re126WWCu}^{\mathbf{I}}\right\}_{2}$ (Figure 8) shows predominant hole localization on W124, with much less delocalization over W122' of the neighboring molecule and W124'. The CS1' state, which lies slightly higher in energy, has the hole predominantly on W122', only little delocalized to W124 and W124'. Calculations thus support the occurrence of parallel W124 $\rightarrow *$ Re and W122' $\rightarrow / / *$ Re electron "hops" and the existence of spatially and energetically distinct CS1 and CS1' states. Albeit limited, the hole delocalization indicates intermolecular (W122' W124), as well as intramolecular (W122'-W124') electronic coupling. Of interest also is minor hole delocalization from $\mathrm{W} 124^{\circ+}(\mathrm{CS} 1)$ and $\left(\mathrm{W} 124^{\circ+}\right)^{\prime}$ (CS1') over the $\mathrm{CH}_{2}$ group to the peptide backbone.

For Re126WFCu, the crystal structure (Figure 1D) indicates pairing through Re complexes by dmp-dmp stacking. The W124' indole of a neighboring molecule is in contact with the excited Re label, as is W124 on the same protein molecule. Both intra- and intermolecular $\mathrm{ET}_{\text {hop }}$ can be operational but without oxidizing either of the $\mathrm{Cu}^{\mathrm{I}}$ atoms that remain too far and decoupled from the *Re126W124//W124' site.

In addition to characterizing photogenerated intermediates and providing kinetics information, ${ }^{29}$ TRIR spectra also revealed that $*$ Re and its binding site undergo cooling and structural relaxation ${ }^{30,35}$ on the same time scale as forward ET from neighboring W124 and/or W122'. Electron and structural dynamics thus seem to be (partly) coupled, which could influence both the driving force and reorganization energy. ${ }^{29}$ In addition, CS1 is, in the initial reaction phases, formed unequilibrated (hot) and its relaxation extends into the

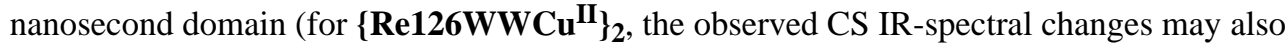
reflect redistribution of the "hole" within the tryptophan quadruplex).

\section{CONCLUDING REMARKS}

Investigations of tryptophan-containing azurin mutants keep revealing new aspects of longrange electron transport and design principles for functional protein-based systems. Tryptophan facilitates ET in azurins by two mechanisms: increasing electronic coupling along single-step tunneling pathways (ca. 3.5 -fold) ${ }^{9}$ and by enabling long-range multistep tunneling (hopping) that results in 100- and 10,000-fold ET accelerations in

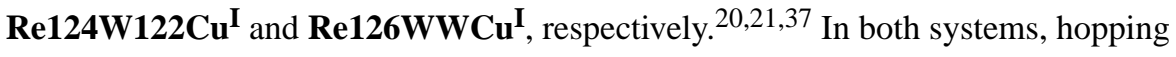


accelerates forward electron transport from $\mathrm{Cu}^{\mathrm{I}}$ to the electronically excited Re label, whereas back ET occurs as (much slower) single-step tunneling. This combination of mechanisms has a "rectification" effect on photoinduced electron transport, resulting in very fast formation of a long-lived $\mathrm{Cu}^{\mathrm{II}}$-containing redox product (RP, $120 \mu$ s in the case of

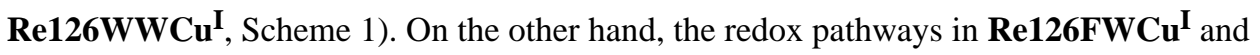
Re126WFCu ${ }^{I}$ are disconnected (one next to the Re sensitizer, the other next to the $\mathrm{Cu}$ site). Hence, photoinduced ET does not occur in the Re126FWCuI monomer and the Re126WFCuI ${ }^{\mathbf{I}}$ ET photocycle is restricted to the Re126W124 unit.

The kinetics and mechanisms of $\mathrm{ET}_{\text {hop }}$ through tryptophan chains in azurin mutants change upon dimer formation, whereby the two protein molecules pair through redox-active regions. Notably, we have observed an onset of $\mathrm{ET}_{\text {hop }}$ reactivity when redox cofactors are in close proximity at the protein-protein interface in $\left\{\operatorname{Re} 126 F W C \mathbf{C u}^{I}\right\}_{2}$. In the case of $\left\{\operatorname{Re126WWCu}^{\mathbf{I}}\right\}_{2}$, competition and crossover between inter- and intramolecular pathways, as well as transient hole trapping take place in an interfacial quadruplex of tightly spaced tryptophans, resembling charge splitting in guanine quadruplexes. ${ }^{38}$ The redox-product lifetime is $\sim 80 \times$ diminished relative to the monomer since the interfacial recombination ET pathway is shorter than the intramolecular one.

Hole hopping through protein complexes is common in natural systems, including cytochrome $c$ peroxidase, ${ }^{39,40,41}$ multicopper oxidases, ${ }^{2}$ and ribonucleotide reductase. 42,43,44 Hopping between interfacial aromatic amino acids can protect enzymes from oxidative damage. ${ }^{17,24,26,27}$ Of interest is that reactions of a sensitizer-modified ribonucleotide reductase can be promoted by photoinduced proton-coupled hopping across a subunit interface. ${ }^{45,46}$ Our understanding of hole hopping through structurally characterized protein-protein interfaces could aid in designing artificial (photo)enzymes to drive substrate redox transformations, as well as molecules and materials for bioelectronic applications, $47,48,49,50$ where intermolecular electron hopping contacts could be engineered into protein films to facilitate solid-state electron transport.

\section{MATERIALS AND METHODS}

\section{Materials.}

Pseudomonas aeruginosa all-Phe azurin (H83Q/Y72F/Y108F/W48F) mutants K122W/ T124W/T126H, K122F/T124W/T126H, and K122W/T124F/T126H were prepared, labeled with $\left[\operatorname{Re}\left(\mathrm{H}_{2} \mathrm{O}\right)(\mathrm{CO})_{3}(\mathrm{dmp})\right](\mathrm{OTf})$, and handled as described previously. ${ }^{21}$ Reduction to $\mathrm{Cu}^{\mathrm{I}}$ was performed by slow stepwise addition of the smallest possible amount of concentrated (typically $6 \times 10^{-2} \mathrm{M}$ ) sodium dithionate solution. (Typically $8 \mu \mathrm{L}$ of $1-2 \mathrm{mM}$ azurin solution plus 1-2 $\mu \mathrm{L}$ dithionate.) For TRIR experiments, azurin solutions $(\sim 8 \mu \mathrm{L})$ were placed in a Hellma $\mathrm{CaF}_{2}$ microcell with $50 \mu \mathrm{m}$ deep, $7 \mathrm{~mm}$ diameter depression with an optical-quality surface and covered with a $\mathrm{CaF}_{2}$ window. The cell was raster-scanned in two dimensions during the measurement to prevent photodecomposition. Hellma fluorescence microcells (optical path $1.5 \times 1.5 \mathrm{~mm}$ ) were used for TCSPC measurements.

Time-resolved infrared spectroscopy (TRIR) experiments were carried out at the Central Laser Facility, STFC Rutherford Appleton Laboratory (UK) on the ULTRA instrument that 
was described in detail elsewhere. ${ }^{22,51}$ In picosecond experiments, the samples were excited either with 400 or $355 \mathrm{~nm}, 50 \mathrm{fs}$ (fwhm), 1 $\mathrm{JJ}$ laser pulses at $10 \mathrm{kHz}$ repetition rate and probed with ca. $400 \mathrm{~cm}^{-1}$ wide mid-IR pulses of $\sim 50 \mathrm{fs}$ duration The time intervals between pump and probe pulses were controlled by an optical delay line. The spectra were recorded on two 128-element $\mathrm{HgCdTe}$ detectors. Spectral resolution varies from 1.9 to $2.4 \mathrm{~cm}^{-1}$ across the measured range. experiments employed the same probe and detection system that were electronically synchronized with $355 \mathrm{~nm}, 0.7 \mathrm{~ns}, \sim 1 \mu \mathrm{J}$ fwhm pulses. TRIR spectra are shown in a difference mode whereby the positive and negative features correspond to photogenerated transients and bleached ground-state absorption, respectively. Global kinetics fitting of TRIR spectra was performed using the Glotaran software. Time constant values shown in figures of decay and evolution associated spectra are pertinent to the respective experiment shown. Values in kinetics tables are averaged over several independent experiments and reported with $\pm 10-20 \%$ accuracy. Typical spectral and kinetics fits are shown in the SI, Section S4, Figures S10-17.

Luminescence decays of concentrated samples ( $\geq 200 \mu \mathrm{M}$ ) were measured using the timecorrelated single photon counting technique (TCSPC) on an IBH 5000 U SPC instrument equipped with a cooled Hamamatsu R3809U-50 microchannel plate photomultiplier with $\sim 40$ ps time resolution. Samples were excited at $373 \mathrm{~nm}$ with an IBH NanoLED-11 diode laser ( $80 \mathrm{ps}$ fwhm). The signal was kept below $2 \%$ of the light source repetition rate to avoid shortening of the recorded lifetime due to the pile-up effect. Decays were fitted using the iterative reconvolution procedure with IBH DAS6 software to a multiexponential function convoluted with the experimental instrument response function.

\section{Computational details.}

The $\left\{\right.$ Re126WWCu $\mathbf{I}_{\mathbf{2}}$ structure was optimized at quantum mechanical/molecular mechanical (QM/MM) level in Terachem 1.952,53 - Amber $14^{54}$ framework. Parallel optimization of the QM part was performed by Terachem 11.9 or Gaussian $16^{55}$ (G16) program packages. The initial dimer structure was based on the experimental crystal structure. Calculations of the QM part utilized LAN2DZ quasirelativistic effective core pseudopotentials and a corresponding optimized set of basis functions for $\operatorname{Re}^{56}$ and 6-31g(d) polarized double- $\zeta$ basis sets ${ }^{57}$ for remaining atoms. DFT employed the PBE0 hybrid functional, ${ }^{58,59}$ together with an empirical dispersion correction D3. ${ }^{60}$

The QM region contained residues 122-126 (W-G-W-L-H) and the Re-complex; and the rest of the system was in the MM region (Figure S3). The QM region was terminated by linking$\mathrm{H}$-atoms, which were attached to the $\mathrm{C}$ alpha atom on the protein backbone. This system was solvated by 2088 SPC/E water molecules ${ }^{61}$, resulting in minimum $28 \AA$ water shell around central Trp residues; $2 \mathrm{Na}^{+}$cations ${ }^{62}$ were added (in proximity of negatively charged residues ASP21, and ASP191) to compensate the charge of the protein chain. The solvent continuum within G16 was described by a polarizable continuum model (PCM). ${ }^{63}$. The lowest lying excitations were calculated by TDDFT approach at QM/MM and QM optimized structures. 


\title{
Supplementary Material
}

Refer to Web version on PubMed Central for supplementary material.

\section{ACKNOWLEDGMENTS}

\begin{abstract}
This work was supported by the National Institute of Diabetes and Digestive and Kidney Diseases of the National Institutes of Health under award number R01DK019038. The content is solely the responsibility of the authors and does not necessarily represent the official views of the National Institutes of Health. Further support was provided the Czech Science Foundation (GAČR) grant 17-011375, the Czech Ministry of Education (MŠMT) grant LTAUSA18026, "IT4Innovations National Supercomputing Center - LM2015070", EPSRC grant (UK) EP/ R029687/1, the STFC Rutherford Appleton Laboratory (UK), and the Arnold and Mabel Beckman Foundation. We thank Dr. Hana Kvapilová (JH Institute) for her help with measuring TRIR spectra. Yuling Shen (Caltech) is acknowledged for her help with protein preparation.
\end{abstract}

\section{References}

1. Winkler JR; Gray HB, Electron Flow through Metalloproteins. Chem. Rev 2014, 114, 3369-3380. [PubMed: 24279515]

2. Farver O; Pecht I, Electron transfer in blue copper proteins. Coord. Chem. Rev 2011, 255, 757-773.

3. Winkler JR; Di Bilio AJ; Farrow NA; Richards JH; Gray HB, Electron tunneling in biological molecules. Pure Appl. Chem 1999, 71, 1753-1764.

4. Di Bilio AJ; Hill MG; Bonander N; Karlsson BG; Villahermosa RM; Malmström BG; Winkler JR; Gray HB, Reorganization Energy of Blue Copper: Effects of Temperature and Driving Force on the Rates of Electron Transfer in Ruthenium- and Osmium-Modified Azurins. J. Am. Chem. Soc 1997, 119, 9921-9922.

5. Skov LK; Pascher T; Winkler JR; Gray HB, Rates of Intramolecular Electron Transfer in Ru(bpy)2(im)(His83)-Modified Azurin Increase below 220 K. J. Am. Chem. Soc 1998, 120, 1102 1103.

6. Grădinaru C; Crane BR, Comparison of Intra- vs Intermolecular Long-Range Electron Transfer in Crystals of Ruthenium-Modified Azurin. J. Phys. Chem. B 2006, 110, 20073-20076. [PubMed: 17034174]

7. Farver O; Pecht I, Long Range Intramolecular Electron Transfer in Azurins. J. Am. Chem. Soc 1992, 114, 5764-5767.

8. Farver O; Marshall NM; Wherland S; Lu Y; Pecht I, Designed azurins show lower reorganization free energies for intraprotein electron transfer. Proc. Natl. Acad. Sci. U.S.A 2013, 110, 10536 10540. [PubMed: 23759745]

9. Farver O; Skov LK; Young S; Bonander N; Karlsson BG; Vänngård T; Pecht I, Aromatic Residues May Enhance Intramolecular Electron Transfer in Azurin. J. Am. Chem. Soc 1997, 119, 54535454.

10. van de Kamp M; Floris R; Hali FC; Canters GW, Site-Directed Mutagenesis Reveals That the Hydrophobic Patch of Azurin Mediates Electron Transfer. J. Am. Chem. Soc 1990, 112, 907-908.

11. Beratan DN; Liu C; Migliore A; Polizzi NF; Skourtis SS; Zhang P; Zhang Y, Charge Transfer in Dynamical Biosystems, or The Treachery of (Static) Images. Acc. Chem. Res 2015, 48, 474-481. [PubMed: 25307316]

12. Beratan DN; Spiros S Skourtis SS; Balabin IA; Balaeff A; Shahar Keinan S; Ravindra Venkatramani R; Dequan Xiao D, Steering Electrons on Moving Pathways. Acc. Chem. Res 2009, 42, 1669-1678. [PubMed: 19645446]

13. Skourtis SS; Balabin IA; Kawatsu T; Beratan DN, Protein dynamics and electron transfer: Electronic decoherence and non-Condon effects. Proc. Natl. Acad. Sci. USA 2005, 102, 35523557. [PubMed: 15738409]

14. Regan JJ; Onuchic JN, Electron Transfer Tubes. Adv. Chem. Phys 1999, 107, 497-554.

15. Narth C; Gillet N; Cailliez F; Lévy B; Aurélien de la Lande, A., Electron Transfer, Decoherence, and Protein Dynamics: Insights from Atomistic Simulations. Acc. Chem. Res 2015, 48, 10901097. [PubMed: 25730126] 
16. Kretchmer JS; Boekelheide N; Warren JJ; Winkler JR; Gray HB; Miller III TF, Fluctuating hydrogen-bond networks govern anomalous electron transfer kinetics in a blue copper protein. Proc. Natl. Acad. Sci. U.S.A 2018, 115, 6129-6134. [PubMed: 29844178]

17. Winkler JR; Gray HB, Long-Range Electron Tunneling. J. Am. Chem. Soc 2014, 136, 2930-2939. [PubMed: 24499470]

18. Warren JJ; Winkler JR; Gray HB, Hopping maps for photosynthetic reaction centers. Coord. Chem. Rev 2013, 257, 165-170. [PubMed: 23275678]

19. Gray HB; Winkler JR, Electron tunneling through proteins. Q. Rev. Biophys 2003, 36, 341-372. [PubMed: 15029828]

20. Shih C; Museth AK; Abrahamsson M; Blanco-Rodriguez AM; Di Bilio AJ; Sudhamsu J; Crane BR; Ronayne KL; Towrie M; Vlček A, Jr; Richards JH; Winkler JR; Gray HB, TryptophanAccelerated Electron Flow Through Proteins. Science 2008, 320, 1760-1762. [PubMed: 18583608]

21. Takematsu K; Williamson HR; Nikolovski P; Kaiser JT; Sheng Y; Pospíšil P; Towrie M; Heyda J; Hollas D; Záliš S; Gray HB; Vlček A; Winkler JR, Two tryptophans are better than one in accelerating electron flow through a protein. ACS Cent. Sci, DOI: 10.1021/acscentsci.8b00882 2019.

22. Takematsu K; Williamson H; Blanco-Rodríguez AM; Sokolová L; Nikolovski P; Kaiser JT; Towrie M; Clark IP; Vlček A, Jr.; Winkler JR; Gray HB, Tryptophan-accelerated electron flow across a protein-protein interface. J. Am. Chem. Soc 2013, 135, 15515-15525. [PubMed: 24032375]

23. Warren JJ; Herrera N; Hill MG; Winkler JR; Gray HB, Electron Flow through Nitrotyrosinate in Pseudomonas aeruginosa Azurin. J. Am. Chem. Soc 2013, 135, 11151-11158. [PubMed: 23859602]

24. Gray HB; Winkler JR, The Rise of Radicals in Bioinorganic Chemistry. Isr. J. Chem 2016, 56, 640-648 [PubMed: 28239191]

25. Gupta A; Nederlof I; Sottini S; Tepper AWJW; Groenen EJJ; Thomassen EAJ; Canters GW, Involvement of Tyr108 in the Enzyme Mechanism of the Small Laccase from Streptomyces coelicolor. J. Am. Chem. Soc 2012, 134, 18213-18216. [PubMed: 23094962]

26. Gray HB; Winkler JR, Hole hopping through tyrosine/tryptophan chains protects proteins from oxidative damage. Proc. Natl. Acad. Sci. U.S.A 2015, 112, 10920-10925. [PubMed: 26195784]

27. Winkler JR; Gray HB, Electron flow through biological molecules: does hole hopping protect proteins from oxidative damage? QRB Discovery 2015, 48, 411-420.

28. Sokolová L; Williamson H; Sýkora J; Hof M; Gray HB; Brutschy B; Vlček A, Jr., Mass Spectrometric Characterization of Oligomers in Pseudomonas aeruginosa Azurin Solutions. J. Phys. Chem. B 2011, 115, 4790-4800. [PubMed: 21452827]

29. Vlček A; Kvapilová H; Towrie M; Záliš S, Electron-Transfer Acceleration Investigated by Time Resolved Infrared Spectroscopy. Acc. Chem. Res 2015, 48, 868-876. [PubMed: 25699661]

30. Blanco-Rodríguez AM; Busby M; Ronayne KL; Towrie M; Grădinaru C; Sudhamsu J; Sýkora J; Hof M; Záliš S; Di Bilio AJ; Crane BR; Gray HB; Vlček A, Jr., Relaxation Dynamics of $\left[\operatorname{Re}^{\mathrm{I}}(\mathrm{CO})_{3}(\mathrm{phen})(\text { HisX) }]^{+}(\mathrm{X}=83,107,109,124,126)\right.$ Pseudomonas aeruginosa Azurins. J. Am. Chem. Soc 2009, 131, 11788-11800. [PubMed: 19639996]

31. Horng ML; Gardecki JA; Papazyan A; Maroncelli M, Subpicosecond Measurements of Polar Solvation Dynamics: Coumarin 153 Revisited. J. Phys. Chem 1995, 99, 17311-17337.

32. Vlček A, Jr., Ultrafast Excited-State Processes in Re(I) Carbonyl-Diimine Complexes: From Excitation to Photochemistry. Top. Organomet. Chem 2010, 29, 73-114.

33. Dattelbaum DM; Omberg KM; Hay PJ; Gebhart NL; Martin RL; Schoonover JR; Meyer TJ, Defining Electronic Excited States Using Time-Resolved Infrared Spectroscopy and Density Functional Theory Calculations. J. Phys. Chem. A 2004, 108, 3527-3536.

34. Dattelbaum DM; Omberg KM; Schoonover JR; Martin RL; Meyer TJ, Application of TimeResolved Infrared Spectroscopy to Electronic Structure in Metal-to-Ligand Charge-Transfer Excited States. Inorg. Chem 2002, 41, 6071-6079. [PubMed: 12425635]

35. Liard DJ; Busby M; Matousek P; Towrie M; Vlček A, Jr., Picosecond Relaxation of ${ }^{3}$ MLCT Excited States of $\left[\operatorname{Re}(\operatorname{Etpy})(\mathrm{CO})_{3}(\mathrm{dmb})\right]^{+}$and $\left[\operatorname{Re}(\mathrm{Cl})(\mathrm{CO})_{3}(\right.$ bpy $\left.)\right]$ as Revealed by Time-Resolved 
Resonance Raman, IR and UV-Vis Absorption Spectroscopy. J. Phys. Chem. A 2004, 108, 23632369.

36. El Nahhas A; Consani C; Blanco-Rodríguez AM; Lancaster KM; Braem O; Cannizzo A; Towrie M; Clark IP; Záliš S; Chergui M; Vlček A, Jr., Ultrafast Excited-State Dynamics of Rhenium(I) Photosensitizers $\left[\operatorname{Re}(\mathrm{Cl})(\mathrm{CO})_{3}(\mathrm{~N}, \mathrm{~N})\right]$ and $\left[\mathrm{Re}(\text { imidazole })(\mathrm{CO})_{3}(\mathrm{~N}, \mathrm{~N})\right]^{+}$: Diimine Effects. Inorg. Chem 2011, 50, 2932-2943. [PubMed: 21388162]

37. Blanco-Rodríguez AM; Di Bilio AJ; Shih C; Museth AK; Clark IP; Towrie M; Cannizzo A; Sudhamsu J; Crane BR; Sýkora J; Winkler JR; Gray HB; Záliš S; Vlček A, Jr., Phototriggering Electron Flow through ReI-modified Pseudomonas aeruginosa Azurins. Chem. Eur. J 2011, 17, 5350-5361. [PubMed: 21469225]

38. Sha R; Xiang L; Liu C; Balaeff A; Zhang Y; Zhang P; Li Y; Beratan DN; Tao N; Seeman NCS, Charge splitters and charge transport junctions based on guanine quadruplexes. Nat. Nanotech 2018, 13, 316-321.

39. Jiang N; Kuznetsov A; Nocek JM; Hoffman BM; Crane BR; Hu X; Beratan DN, DistanceIndependent Charge Recombination Kinetics in Cytochrome $c$-Cytochrome $c$ Peroxidase Complexes: Compensating Changes in the Electronic Coupling and Reorganization Energies. J. Phys. Chem. B 2013, 117, 9129-9141. [PubMed: 23895339]

40. Hoffman BM; Celis LM; Cull DA; Patel AD; Seifert JL; Wheeler KE; Wang J; Yao J; Kurnikov IV; Nocek JM, Differential influence of dynamic processes on forward and reverse electron transfer across a protein-protein interface. Proc. Natl. Acad. Sci. USA 2005, 102, 3564-3569. [PubMed: 15738411]

41. Seifert JL; Pfister TD; Nocek JM; Lu Y; Hoffman BM, Hopping in the Electron-Transfer Photocycle of the 1:1 Complex of Zn-Cytochrome c Peroxidase with Cytochrome c. J. Am. Chem. Soc 2005, 127, 5750-5751. [PubMed: 15839648]

42. Minnihan EC; Nocera DG; Stubbe J, Reversible, Long-Range Radical Transfer in E. coli Class Ia Ribonucleotide Reductase. Acc. Chem. Res 2013, 46, 2524-2535 [PubMed: 23730940]

43. Sjöberg BM; Reichard P, Nature of the free radical in ribonucleotide reductase from Escherichia coli. J. Biol. Chem 1977, 252, 536-541. [PubMed: 188819]

44. Ehrenberg A; Reichard P, Electron Spin Resonance of the Iron - containing Protein B2 from Ribonucleotide Reductase. J. Biol. Chem 1972, 247, 3485-3488. [PubMed: 4337857]

45. Olshansky L; Stubbe J; Nocera DG, Charge-Transfer Dynamics at the $a / \beta$ Subunit Interface of a Photochemical Ribonucleotide Reductase. J. Am. Chem. Soc 2016, 138, 1196-1205. [PubMed: 26710997]

46. Olshansky L; Greene BL; Finkbeiner C; Stubbe J; Nocera DG, Photochemical Generation of a Tryptophan Radical within the Subunit Interface of Ribonucleotide Reductase. Biochemistry 2016, 55, 3234-3240. [PubMed: 27159163]

47. Ron I; Pecht I; Sheves M; Cahen D, Proteins as Solid-State Electronic Conductors. Acc. Chem. Res 2010, 43, 945-953. [PubMed: 20329769]

48. Yu X; Lovrincic R; Sepunaru L; Li W; Vilan A; Pecht I; Sheves M; Cahen D, Insights into SolidState Electron Transport through Proteins from Inelastic Tunneling Spectroscopy: The Case of Azurin. ACS Nano 2015, 10, 9955-9963.

49. Sepunaru L; Pecht I; Sheves M; Cahen D, Solid-State Electron Transport across Azurin: From a Temperature-Independent to a Temperature-Activated Mechanism. J. Am. Chem. Soc 2011, 133, 2421-2423. [PubMed: 21294546]

50. Li W; Sepunaru L; Amdursky N; Cohen SR; Pecht I; Sheves M; Cahen D, Temperature and Force Dependence of Nanoscale Electron Transport via the Cu Protein Azurin. ACS Nano 2012, 6, 10816-10824. [PubMed: 23136937]

51. Greetham G; Burgos P; Cao Q; Clark IP; Codd P; Farrow R; George MW; Kogimtzis M; Matousek P; Parker AW; Pollard M; Robinson D; Xin Z-J; Towrie M, ULTRA - A Unique Instrument for Time-resolved Spectroscopy. Applied Spectroscopy 2010, 64, 1311-1319. [PubMed: 21144146]

52. Ufimtsev IS; Martínez TJ, Quantum Chemistry on Graphical Processing Units. 3. Analytical Energy Gradients and First Principles Molecular Dynamics. J. Chem. Theor. Comp 2009, 5, 26192628. 
53. Titov AV; Ufimtsev IS; Luehr N; Martínez TJ, Generating Efficient Quantum Chemistry Codes for Novel Architectures. J. Chem. Theor. Comp 2013, 9, 213-221.

54. Case DA; Babin V; Berryman JT; Betz RM; Cai Q; Cerutti DS; T.E. Cheatham I; Darden TA; Duke RE; Gohlke H; Goetz AW; Gusarov S; Homeyer N; Janowski P; Kaus J; Kolossváry I; Kovalenko A; Lee TS; LeGrand S; Luchko T; Luo R; Madej B; Merz KM; Paesani F; Roe DR; Roitberg A; Sagui C; Salomon-Ferrer R; Seabra G; Simmerling CL; Smith W; Swails J; Walker RC; Wang J; Wolf RM; Wu X; Kollman PA AMBR 14, University of Caifornia, San Franciso, 2014.

55. Frisch MJ; Trucks GW; Schlegel HB; Scuseria GE; Robb MA; Cheeseman JR; Scalmani G; Barone V; Petersson GA; Nakatsuji H; Li X; Caricato M; Marenich AV; Bloino J; Janesko BG; Gomperts R; Mennucci B; Hratchian HP; Ortiz JV; Izmaylov AF; Sonnenberg JL; Williams-Young D; Ding F; Lipparini F; Egidi F; Goings J; Peng B; Petrone A; Henderson T; Ranasinghe D; Zakrzewski VG; Gao J; Rega N; Zheng G; Liang W; Hada M; Ehara M; Toyota K; Fukuda R; Hasegawa J; Ishida M; Nakajima T; Honda Y; Kitao O; Nakai H; Vreven T; Throssell K; J. A. Montgomery J; Peralta JE; Ogliaro F; Bearpark MJ; Heyd JJ; Brothers EN; Kudin KN; Staroverov VN; Keith TA; Kobayashi R; Normand J; Raghavachari K; Rendell AP; Burant JC; Iyengar SS; Tomasi J; Cossi M; Millam JM; Klene M; Adamo C; Cammi R; Ochterski JW; Martin RL; Morokuma K; Farkas O; Foresman JB; Fox DJ Gaussian16, Revision A.03, Gaussian, Inc.: Wallingford, CT, 2016.

56. Hay PJ; Wadt WR, Ab initio effective core potentials for molecular calculations - potentials for K to Au including the outermost core orbitals. J. Chem. Phys, 1985, 82, 299-310.

57. Hehre WJ; Ditchfield R; Pople JA, Self-Consistent Molecular Orbital Methods. XII. Further Extensions of Gaussian-Type Basis Sets for Use in Molecular Orbital Studies of Organic Molecules. J. Chem. Phys 1972, 56, 2257-2261.

58. Adamo C; Barone V, Toward reliable density functional methods without adjustable parameters: The PBE0 model. J. Chem. Phys 1999, 110, 6158-6170.

59. Adamo C; Scuseria GE; Barone V, Accurate excitation energies from time-dependent density functionl theory: Assessing the PBE0 model. J. Chem. Phys 1999, 111, 2889-2899.

60. Grimme S; Antony J; Ehrlich S; Krieg H, A consistent and accurate ab initio parametrization of density functional dispersion correction (DFT-D) for the 94 elements H-Pu. J. Chem. Phys 2010, 132, 154104.

61. Berendsen HJC; Grigera JR; Straatsma TP, The Missing Term in Effective Pair Potentials. J. Phys. Chem 1987, 91, 6269-6271.

62. Heyda J; Pokorna J; Vrbka L; Vacha R; Jagoda-Cwiklik B; Konvalinka J; Jungwirth P; Vondrasek J, Ion Specific Effects of Sodium and Potassium on the Catalytic Activity of HIV-1 Protease. Phys. Chem. Chem. Phys 2009, 11, 7599-7604. [PubMed: 19950498]

63. Cossi M; Barone V; Cammi R; Tomasi J, Ab initio study of solvated molecules: A new implementation of the polarizable continuum model. Chem. Phys. Lett 1996, 255, 327-335. 

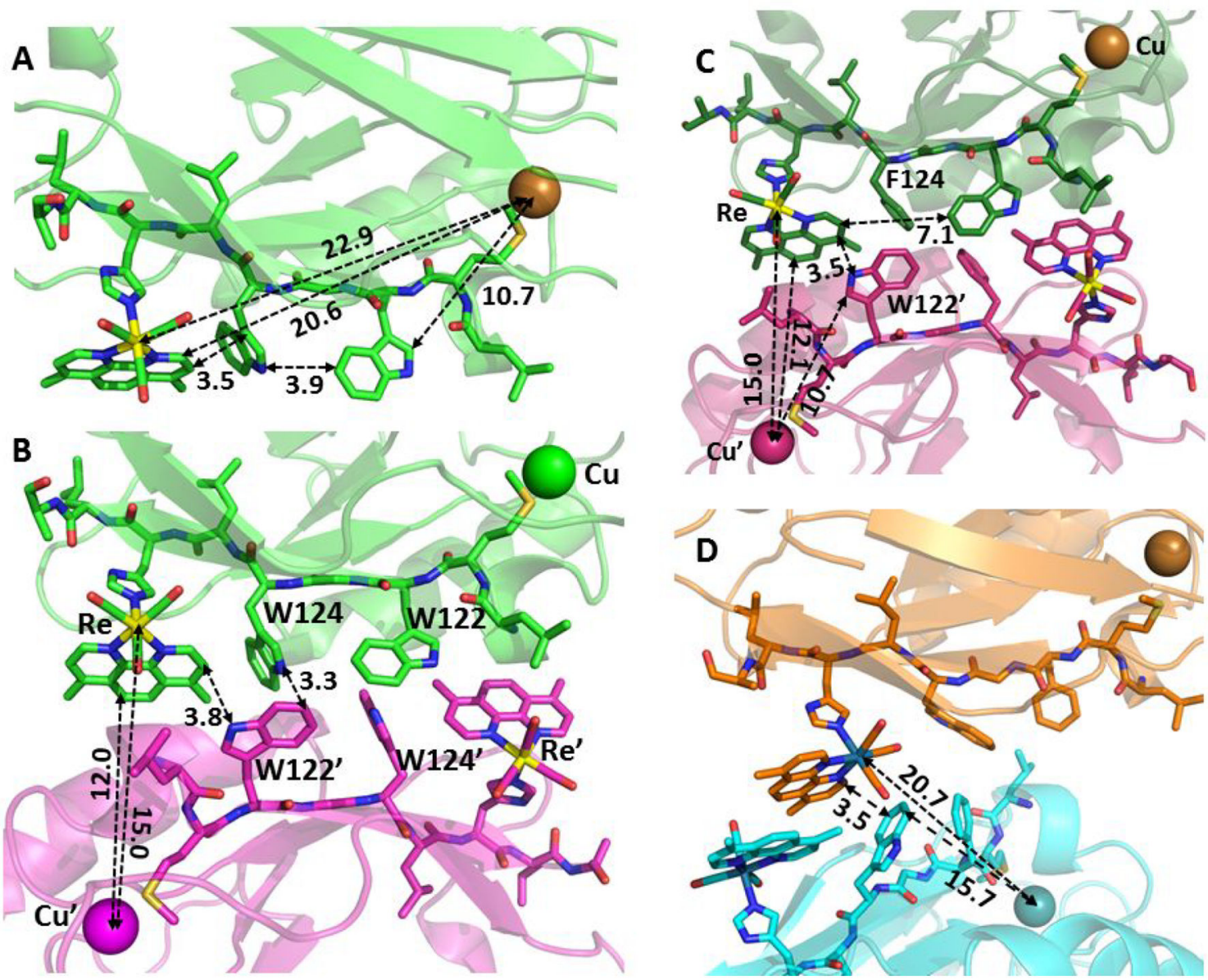

Figure 1.

A: Structure of $\operatorname{Re126WWCu}^{\text {II }}$ (PDB: 6MJS, chain A) showing intramolecular distances between the redox cofactors. B: The interfacial region between chains A and D in the asymmetric unit of $\operatorname{Re126WWCu} \mathbf{u}^{\text {II }}$, showing distances relevant to intermolecular ET. The four interfacial tryptophans form a "cage" with indole groups separated by less than $4 \AA$. C: The interfacial region between chains $\mathrm{A}$ and $\mathrm{C}$ in the asymmetric unit of $\mathbf{R e 1 2 6 F W C u} \mathbf{u}^{\mathrm{II}}$, showing distances relevant to intermolecular ET. D: The interfacial region of $\mathbf{R e 1 2 6 W F C u}^{\text {II }}$ showing distances relevant to intermolecular ET. A Pymol-generated symmetry match to the

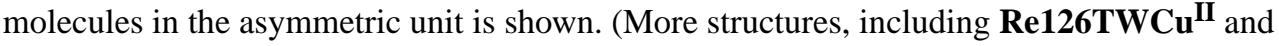
ReW122CuII, are shown in Figure S1.) 


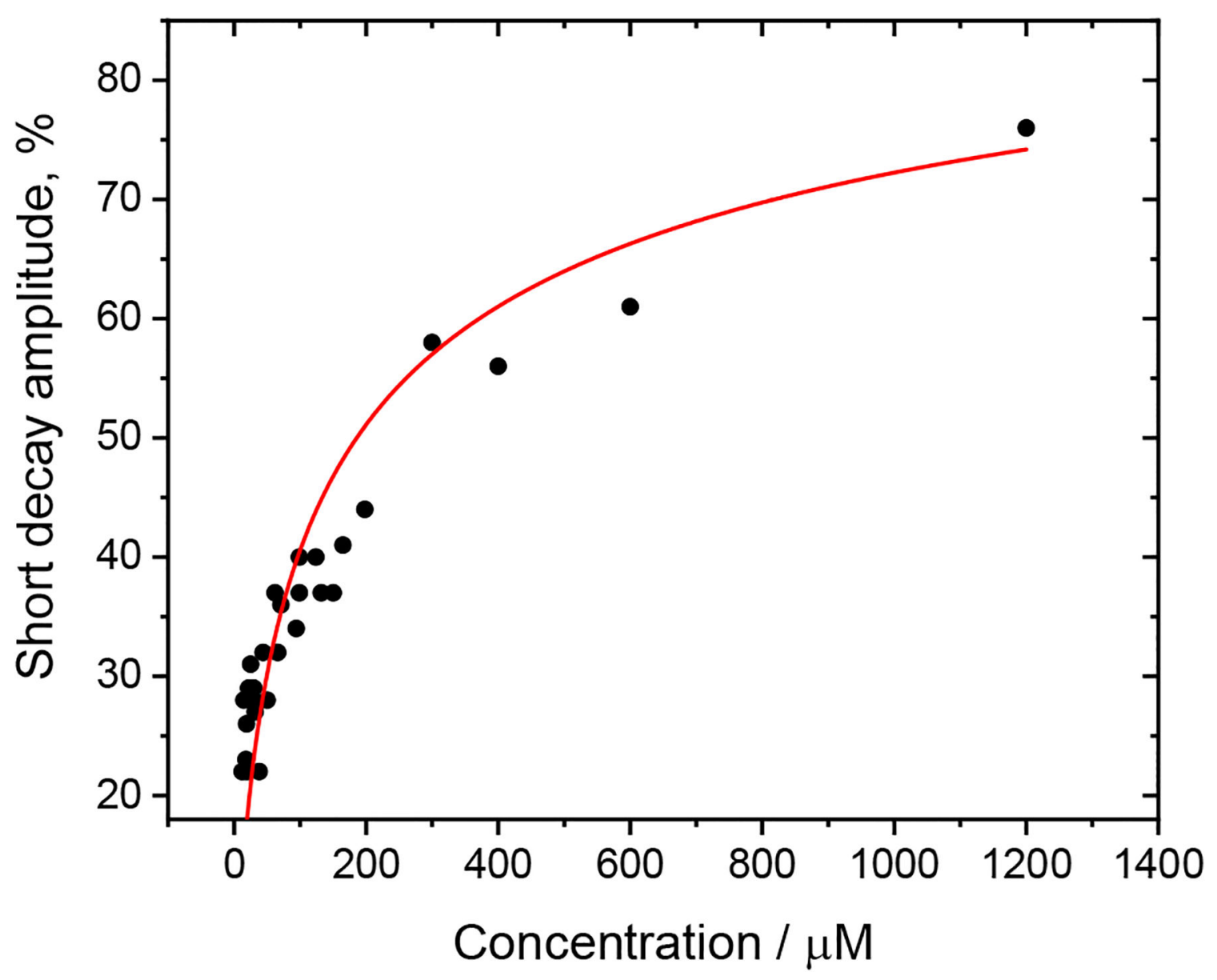

Figure 2.

Concentration dependence of the amplitude of the short emission decay component(s) of Re126FWCu ${ }^{\text {II }}$ in $\mathrm{H}_{2} \mathrm{O}, 20 \mathrm{mM} \mathrm{NaP}_{\mathrm{i}}, \mathrm{pH} \cong 7.2$. The red curve shows the fit assuming an equilibrium between an unquenched monomer and a partly quenched dimer with a dimerization constant of $1.6 \times 10^{4} \mathrm{M}^{-1}$. Measured over a $12-1400 \mu \mathrm{M}$ range. See section $\mathrm{S} 2.1$. for experimental details and ref. ${ }^{22}$ for the analysis procedure. 

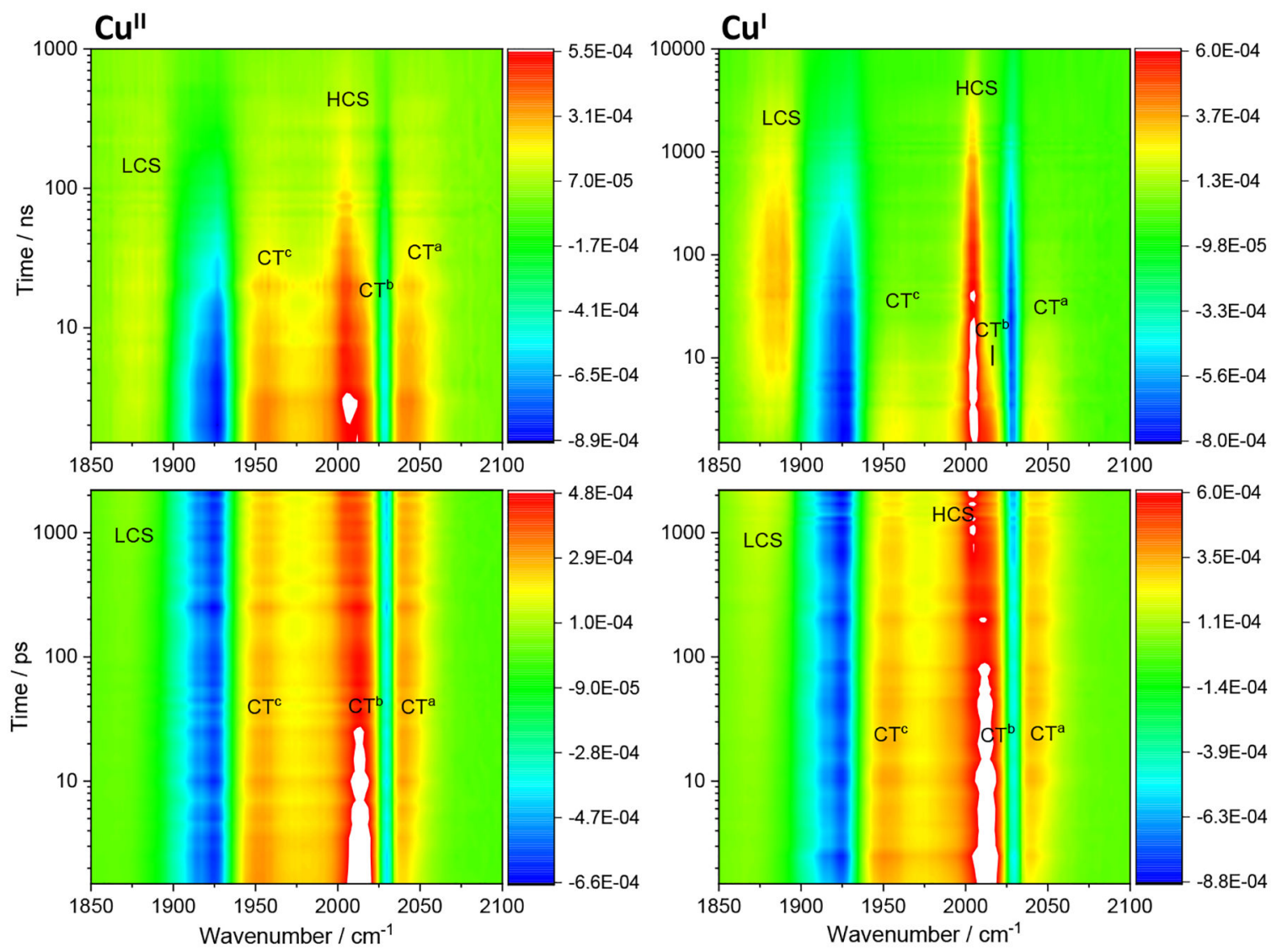

Figure 3.

Difference TRIR spectra of $\operatorname{Re126FWCu}^{\text {II }}$ (left) and $\operatorname{Re126FWCu}^{\mathbf{I}}$ (right). Negative (blue) features correspond to depleted ground-state population; positive features correspond to photogenerated transients (yellow-orange-red-white in the order of increasing intensity). Picosecond spectra (bottom) were measured in $1.2 \mathrm{mM}\left(\mathrm{Cu}^{\mathrm{II}}\right)$ and $1 \mathrm{mM}\left(\mathrm{Cu}^{\mathrm{I}}\right)$ solutions in $\mathrm{D}_{2} \mathrm{O}, 20 \mathrm{mM} \mathrm{KP}, \mathrm{pD} \cong 7.1$ using $400 \mathrm{~nm}, \sim 50$ fs excitation. Nanosecond spectra were measured in $1.3 \mathrm{mM}\left(\mathrm{Cu}^{\mathrm{II}}\right)$ and $0.8 \mathrm{mM}\left(\mathrm{Cu}^{\mathrm{I}}\right)$ solutions in $\mathrm{H}_{2} \mathrm{O}, 20 \mathrm{mM} \mathrm{KP}, \mathrm{pH} \cong 7.1$. Excited with $355 \mathrm{~nm}, \sim 0.7 \mathrm{~ns}$ pulses. CT features $\left(1956, \sim 2012,2042 \mathrm{~cm}^{-1}\right)$ decay with a concomitant rise and later decay of both lower- and higher-lying CS bands (LCS, $1885 \mathrm{~cm}^{-1}$ and HCS, $2004 \mathrm{~cm}^{-1}$ ) and bleach recovery. (Note the 10-times longer time-range in the topright than the top-left panel.) The LCS overlaps with the $1926 \mathrm{~cm}^{-1}$ bleach, hence the $\sim 1885$ $\mathrm{cm}^{-1}$ maximum at $\geq 10 \mathrm{~ns}$ is only apparent. 

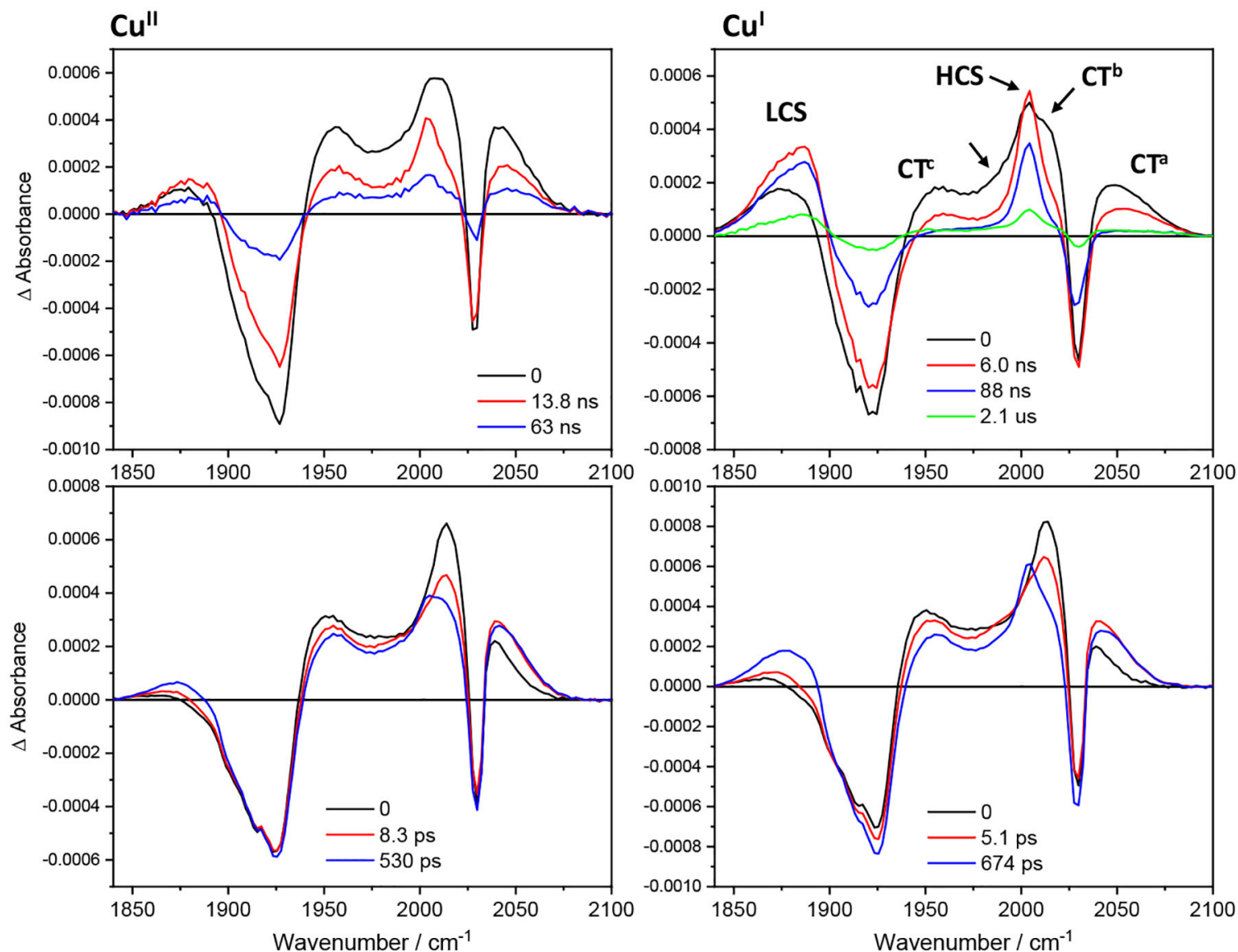

Figure 4.

Evolution associated spectra of $\operatorname{Re126FWCu}^{\text {II }}$ (left) and $\operatorname{Re126FWCu}^{\mathbf{I}}$ (right) obtained by global fit of picosecond (bottom) and nanosecond (top) 3D TRIR data (kinetic/spectral) using a sequential multiexponential model. Black curves are spectra are extrapolated to time 0 and correspond to the species formed within the $355, \sim 0.7$ ns laser pulse excitation. Red, blue and green curves correspond to spectra associated with the specified kinetics. The longest-lifetime spectra correspond to the residual species that remains after a process characterized by the specified time constant and decays on a timescale longer than the measurement. Band labelling in the top-right panel is valid for all spectra shown. The unlabeled arrow indicates the $\sim 1985 \mathrm{~cm}^{-1}$ shoulder. Experimental conditions as in Figure 3, except the top-right spectrum $(0.63 \mathrm{mM})$. 

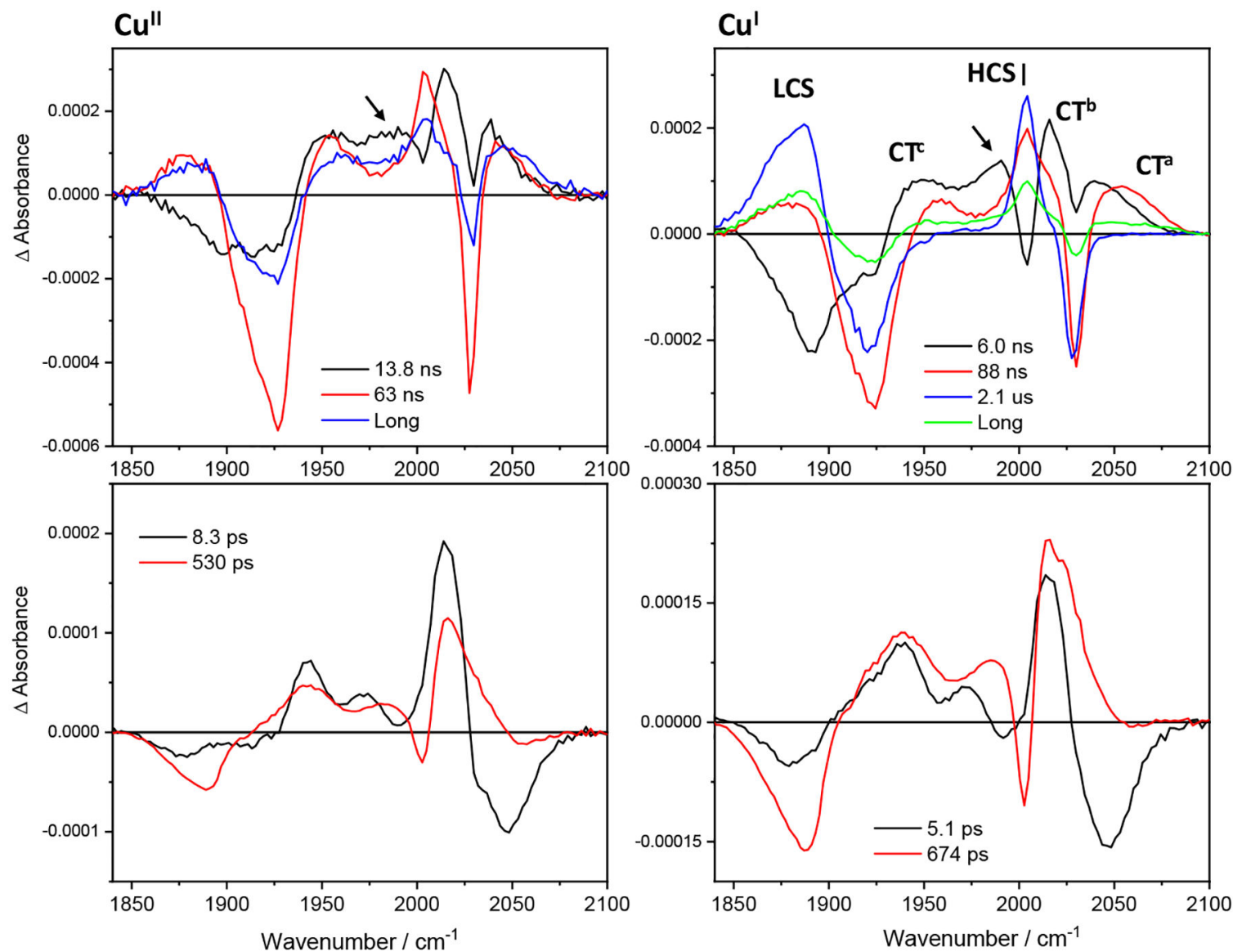

Figure 5.

Decay associated spectra of $\operatorname{Re126FWCu}{ }^{I I}$ (left) and Re126FWCu ${ }^{I}$ (right) obtained by by global fit of picosecond (bottom) and nanosecond (top) 3D TRIR data (kinetic/spectral) using a sequential multiexponential model. Negative and positive features correspond to signal rise and decay, respectively. Band labelling in the top-right panel is valid for all spectra shown. The unlabeled arrow indicates decay of the $\sim 1985 \mathrm{~cm}^{-1}$ shoulder.

Experimental conditions as in Figure 3, except for the top-right spectrum $(0.63 \mathrm{mM})$. 

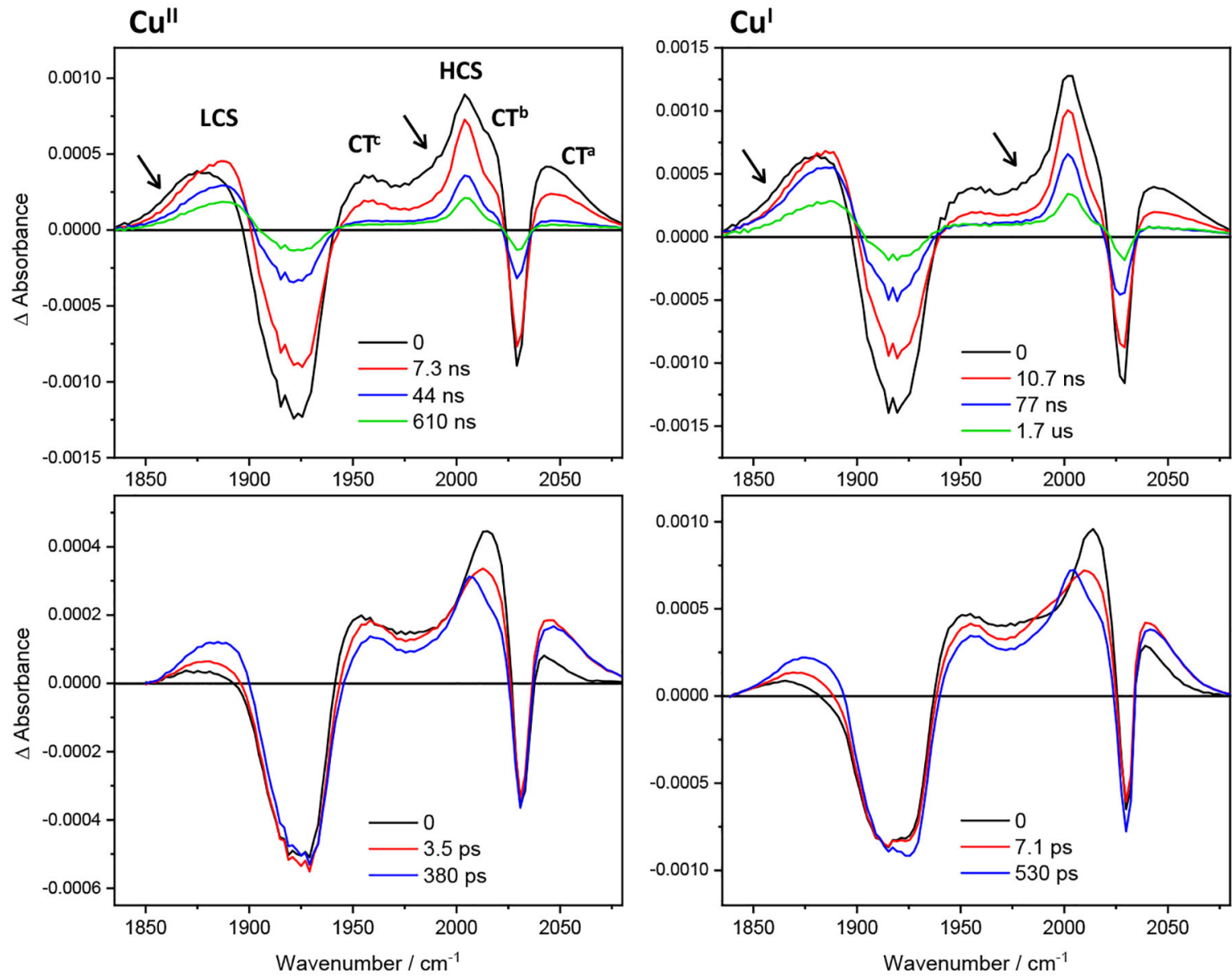

Figure 6.

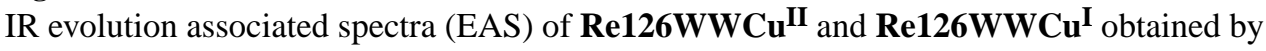
global fit of picosecond (bottom) and nanosecond (top) 3D TRIR data (kinetic/spectral) using a sequential multiexponential model. Black curves are spectra are extrapolated to time 0 and correspond to the species formed within the $50 \mathrm{fs}$ (bottom) or $0.7 \mathrm{~ns}$ (top) laser pulse excitation. Red, blue and green curves correspond to spectra associated with the specified kinetics. The longest-lifetime spectra correspond to the residual species that remains after a process characterized by the specified time constant and decays on a timescale longer than the measurement (120 $\mu$ s assumed ${ }^{21}$ for the top-right spectrum.) Band labelling in the topleft panel is valid for all spectra shown. Arrows indicate the LCS early-time broadening and the $\sim 1985 \mathrm{~cm}^{-1}$ shoulder. Experimental conditions as in Figure S4. 

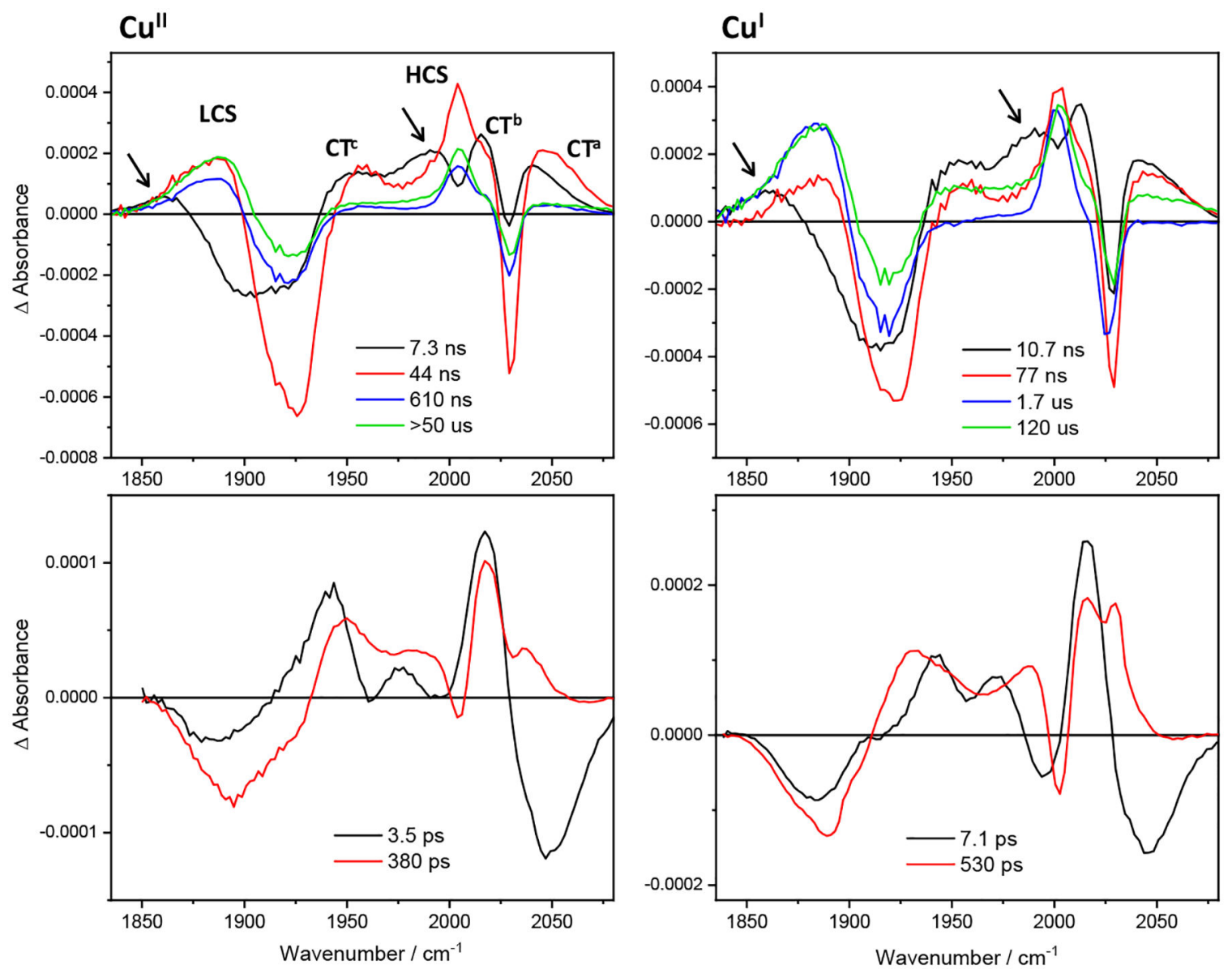

Figure 7.

IR decay associated spectra of Re126WWCuII and $\operatorname{Re126WWCu} \mathbf{I}^{\mathrm{I}}$ obtained by global fit of picosecond (bottom) and nanosecond (top) 3D TRIR data (kinetic/spectral) using a sequential multiexponential model. Negative and positive features correspond to signal rise and decay, respectively. Band labelling in the top-left panel is valid for all spectra shown. Arrows indicate decay of the LCS early-time broadening and of the $\sim 1985 \mathrm{~cm}^{-1}$ shoulder. Experimental conditions as in Figure S4. 

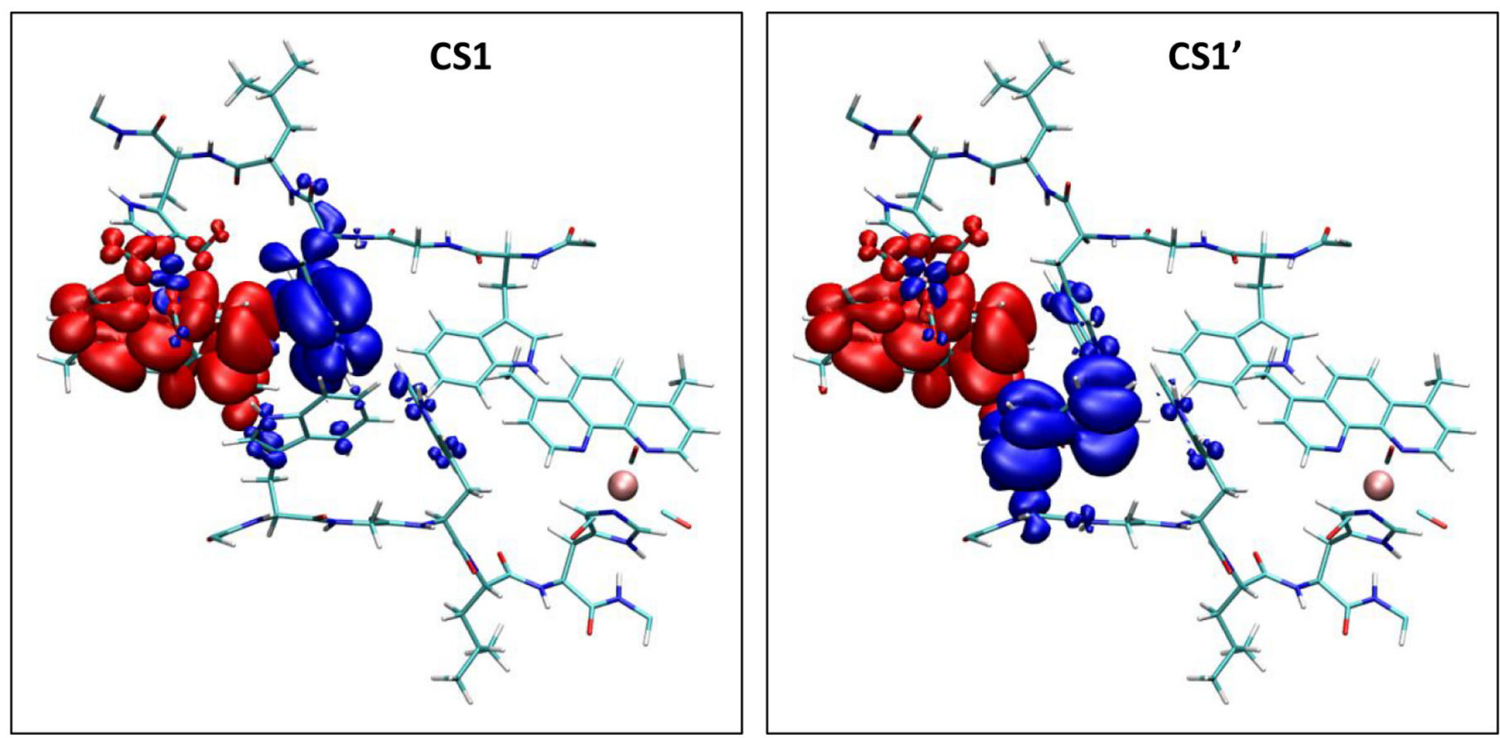

Figure 8.

Electron density difference between the CS1 (left) and CS1' (right) states and the ground state of solvated $\left\{\operatorname{Re126WWCu} \mathbf{I}_{2}\right.$. Red and blue denote regions of increased and depleted electron density, respectively. (TDDFT calculation on the QM/MM-optimized structure.) 


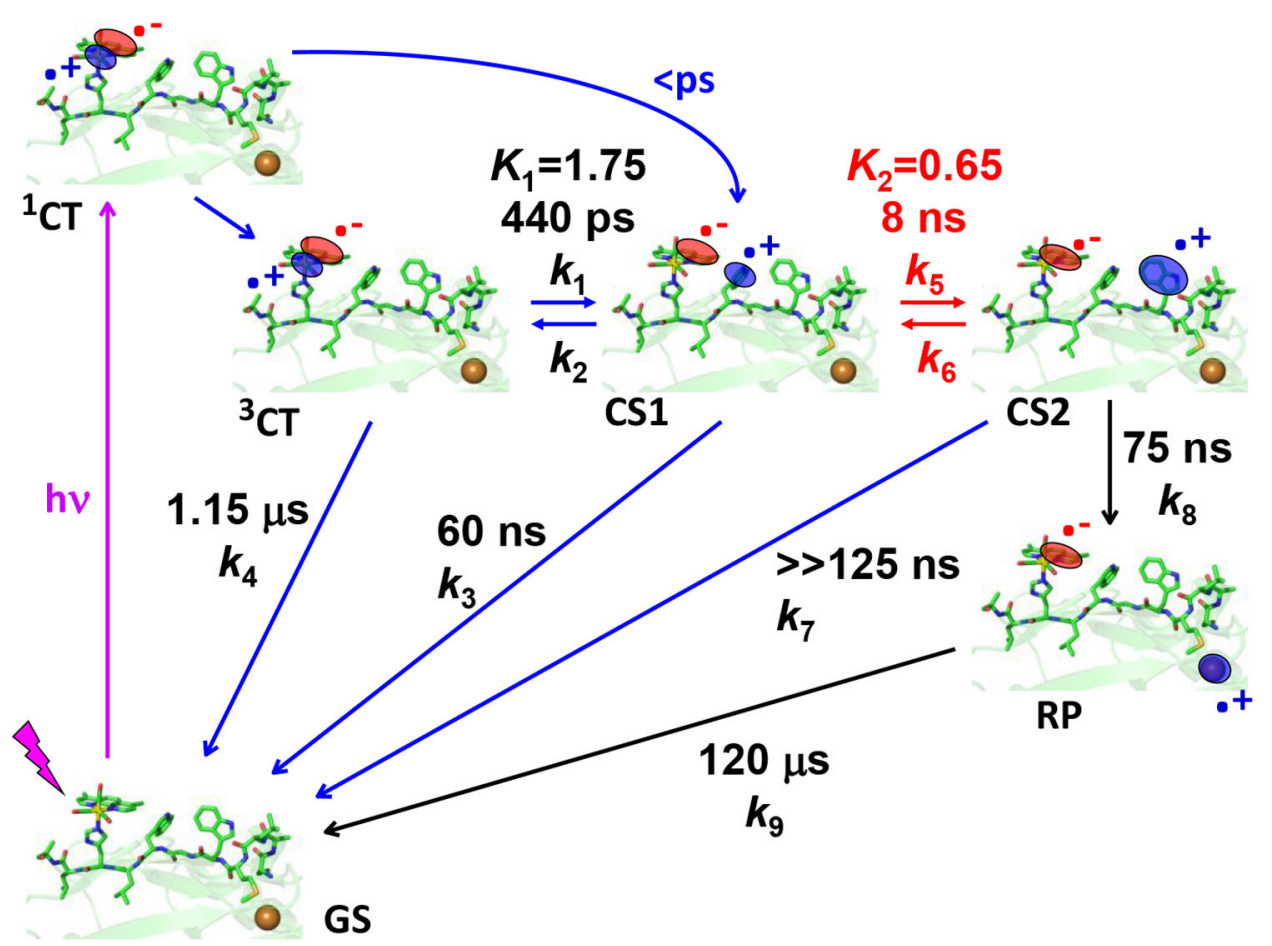

Scheme 1.

Intramolecular photoinduced ET cycle of $\mathbf{R e 1 2 6 W W C u}{ }^{\mathbf{I}}$ as established in ref. ${ }^{21} \mathrm{The} \mathrm{Re}-\mathrm{Cu}$ charge separation takes place via hopping through two Trp residues. ${ }^{3} \mathrm{CT}$ is a mixed $\mathrm{Re} \rightarrow \mathrm{dmp}$ MLCT/dmp-intraligand excited state (*Re) that is populated upon optical excitation of the Re label after ultrafast intersystem crossing and several relaxation steps (not shown). It undergoes reversible $* \mathrm{Re} \leftrightarrow \mathrm{W} 124 \mathrm{ET}$ producing a charge-separated state CS1: $\operatorname{Re}^{\mathrm{I}}(\mathrm{H} 126)(\mathrm{CO})_{3}\left(\mathrm{dmp}^{\bullet-}\right)\left(\mathrm{W} 124^{\bullet+}\right) \mathrm{W} 122 \mathrm{Cu}^{\mathrm{I}}$. The second ET equilibrium W124 ${ }^{\bullet+} \leftrightarrow \mathrm{W} 122$ produces the CS2 state $\operatorname{Re}^{\mathrm{I}}(\mathrm{H} 126)(\mathrm{CO})_{3}\left(\mathrm{dmp}^{\circ-}\right) \mathrm{W} 124\left(\mathrm{~W} 122^{\circ}\right) \mathrm{Cu}^{\mathrm{I}}$. W122 $2^{\circ+}$ then undergoes $\sim 75 \mathrm{~ns}$ reduction by $\mathrm{Cu}^{\mathrm{I}}$ over a $\sim 11 \AA$ distance, forming the redox product (RP) $\operatorname{Re}^{\mathrm{I}}(\mathrm{H} 126)$ $(\mathrm{CO})_{3}\left(\mathrm{dmp}^{\bullet-}\right) \mathrm{W} 124 \mathrm{~W} 122 \mathrm{Cu}^{\mathrm{II}}$. The cycle is completed by $\sim 120 \mu \mathrm{se}\left(\mathrm{dmp}^{\bullet-}\right) \rightarrow \mathrm{Cu}^{\mathrm{II}}$ back electron transfer. The low $K_{2}$ value limits the RP quantum yield. This scheme is also applicable to $\operatorname{Re126WFCu} \mathbf{I}^{\mathbf{I}}\left(k_{5}\right.$ and all subsequent rate constants $\left.=0\right)$ and $\operatorname{Re126FWC\mathbf {u}^{\mathbf {I}}}$ ( $k_{1}$ and all subsequent rate constants $=0 ;\left(k_{4}\right)^{-1}$ is the unquenched ${ }^{3} \mathrm{CT}$ lifetime, $1.15 \mu \mathrm{s}$.) 


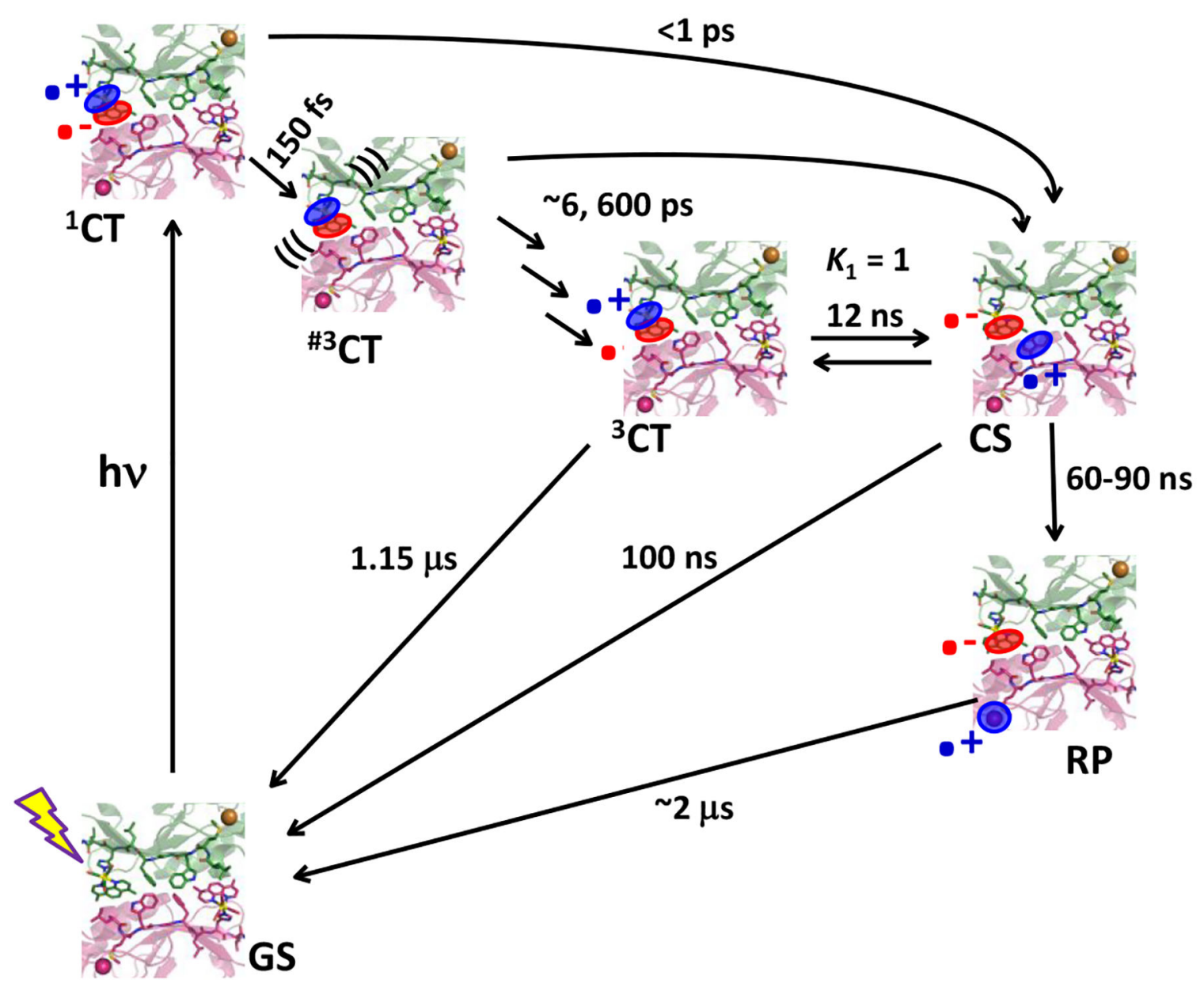

Scheme 2.

The $\left\{\operatorname{Re126} \mathbf{F} \mathbf{W C u}^{\mathbf{I}}\right\}_{2}$ photocycle. Oxidized and reduced sites are shown in blue and red, respectively. The time constants of ${ }^{3} \mathrm{CT} \rightarrow \mathrm{CS}$ and $\mathrm{CS} \rightarrow \mathrm{RP}$ conversions and the $K_{1}$ value were estimated by simulating the kinetics using the model previously applied to Re124W122CuI (formally equivalent to the present case). ${ }^{20}$ Simulations were performed as described in refs. ${ }^{20,21}$ The values shown provided ${ }^{3} \mathrm{CT}$ decay lifetimes of 5.5 and $71 \mathrm{~ns}$, approximately matching the TRIR experiment. The scheme is applicable also to $\mathrm{Cu}^{\mathrm{II}}$-azurin by deleting RP. Reasonable match with experimental $\mathrm{Cu}^{\mathrm{II}}$ luminescence and TRIR data was obtained for $K_{1}=3,10 \mathrm{~ns}{ }^{3} \mathrm{CT} \rightarrow \mathrm{CS}$ and $50 \mathrm{~ns} \mathrm{CS} \rightarrow \mathrm{GS}$ conversions. (Unquenched ${ }^{3} \mathrm{CT}$ lifetimes were fixed as $1.15 \mu \mathrm{s}\left(\mathrm{Cu}^{\mathrm{I}}\right)^{21}$ and $260 \mathrm{~ns}\left(\mathrm{Cu}^{\mathrm{II}}\right.$, Table S3.)) The "hot" ${ }^{3} \mathrm{CT}$ state is denoted by triple brackets. 


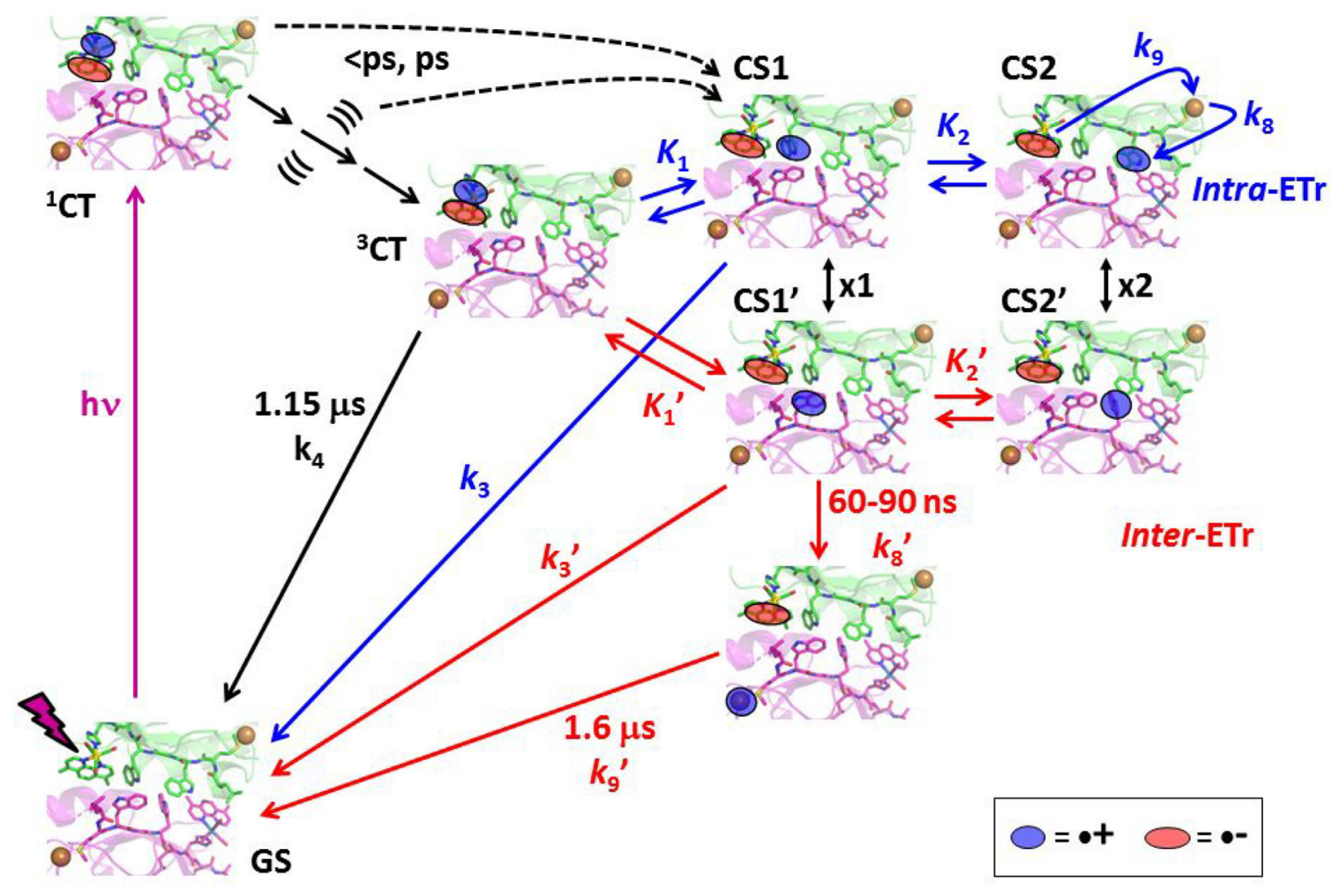

Scheme 3.

Photoinduced electron transfer in $\left\{\operatorname{Re126WWCu}{ }^{\mathbf{I}}\right\}_{2}$. Intermolecular ET steps are shown as red arrows, intramolecular ET in blue, common excited-state steps are in black. ((())) and the three accompanying black arrows denote hot ${ }^{3} \mathrm{CT}$ state(s) and their relaxation, respectively. Intramolecular CS2 recombination $\left(k_{7}\right)$ is omitted for clarity while $\mathrm{Cu}^{\mathrm{I}}$ oxidation $\left(k_{8}\right)$, and the $\sim 120 \mu$ BET $\left(k_{9}\right)$ are only indicated by curved blue arrows. (See Scheme 1 for the intramolecular mechanism.) Intermolecular CS2' decay to the GS is neglected as well; it is assumed ${ }^{21}$ to occur in microseconds. The black double arrows $\mathrm{x} 1$ and $\mathrm{x} 2$ indicate possible crossovers between the intra- and intermolecular pathways. The red pathway is applicable also to the $\mathrm{Cu}^{\mathrm{II}}$ species by setting $k_{8}{ }^{\prime}=k_{9}{ }^{\prime}=0$. Figure S6 affords another depiction of the mechanism. 
Table 1.

Shortest atom-atom intermolecular distances between redox cofactors of Re-azurin mutants. (Only aromatic C and $\mathrm{N}$ atoms, as well as $\mathrm{Re}$ and $\mathrm{Cu}$ are considered. Values were averaged over the molecules comprising the asymmetric unit.)

\begin{tabular}{|c|c|c|c|}
\hline Distance (̊̊) & $\operatorname{Re126WWCu}^{\text {II }}$ & $\operatorname{Re126FWCu}^{\text {II }}$ & $\operatorname{Re126WFCu}^{{ }^{I I}}{ }^{a}$ \\
\hline Re-W122' & 7.0 & 6.6 & 4.6 \\
\hline dmp-W122' & $3.8^{b}$ & $3.5^{c}$ & 3.5 \\
\hline W124-W122' & 3.3 & - & - \\
\hline W124-W124' & $3.5-4.8^{d}$ & & \\
\hline W122-W122' & $3.7^{e}$ & & \\
\hline Cu-dmp' & $12.0^{f}$ & $12.1^{g}$ & 18.7 \\
\hline Cu-Re' & $15.0^{\prime}$ & 15.0 & 20.7 \\
\hline Angle $\left(^{\circ}\right)$ & & & \\
\hline dmp-W122' & $15.1-10.6$ & 23.2 & \\
\hline W124-W122' & $84.4-68.1^{d}$ & - & \\
\hline W124-W124' & $4.3-17.6^{h}$ & - & \\
\hline
\end{tabular}

'a Distances measured to W124'. Two interfaces are present. The shorter distances are listed. Distances between the stacked Re complexes: $9.5 \AA$ (Re-Re'), 3.4 ^̊ (dmp-dmp').

${ }^{b}$ An additional close contact (3.6 ̊) exists between the indole ring and $\mathrm{C}\left(\mathrm{CH}_{3}-\mathrm{dmp}\right)$.

${ }^{c}$ Shortest W122' indole- $\mathrm{C}\left(\mathrm{CH}_{3}-\mathrm{dmp}\right)$ distance $=3.9 \AA$.

$d_{3.5 / 4.8 \AA} \AA$ and $84.4 / 68.1^{\circ}$ correspond to B-C/A-D interfaces.

$e_{\text {T-oriented. }}$

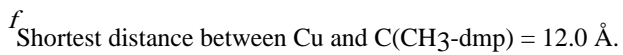

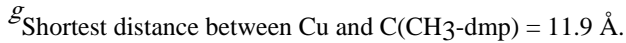

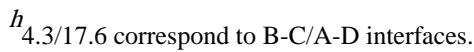


Table 2.

Photochemical kinetics of Re126FWCu at $\sim 1 \mathrm{mM}$ concentration. ${ }^{a}$

\begin{tabular}{|c|c|c|}
\hline $\mathrm{Cu}^{\mathrm{II}}$ & $\mathrm{Cu}^{\mathrm{I}}$ & Underlying processes \\
\hline $8 \mathrm{ps}$ & $5 \mathrm{ps}$ & $\mathrm{CT}$ relaxation ${ }^{b}$ and small CS rise \\
\hline $530 \mathrm{ps}$ & $670 \mathrm{ps}$ & $\mathrm{CT}$ relaxation ${ }^{b}$ and decay; CS rise \\
\hline $14 \mathrm{~ns}$ & $6-8 \mathrm{~ns}$ & $\mathrm{CT}$ relaxation ${ }^{b}$ and decay; CS rise \\
\hline \multirow[t]{3}{*}{$63 \mathrm{~ns}$} & & $\mathrm{CT}$ and CS decay; bleach recovery \\
\hline & $70-90 \mathrm{~ns}$ & $\mathrm{CT}$ and very small CS decay; bleach recovery \\
\hline & $1.2-2.1 \mathrm{~ns}$ & $\mathrm{RP}(\mathrm{CS})^{c}$ decay and bleach recovery \\
\hline$>1 \mu \mathrm{S}$ & $>10 \mu \mathrm{s}$ & very weak residual CS decay and bleach recovery \\
\hline
\end{tabular}

${ }^{a}$ Time constants were obtained by global fitting of pico- and nanosecond TRIR spectra obtained in several independent experiments. Characters of underlying processes were inferred from the evolution- and decay associated spectra (Figures 4, 5).

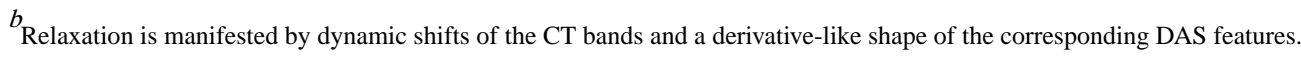

${ }^{c}$ RP spectral features cannot be distinguished from those of CS (LCS, HCS). 
Table 3.

Photochemical kinetics of Re126WWCu at $\sim 1 \mathrm{mM}$ concentration. ${ }^{a}$

\begin{tabular}{|c|c|c|}
\hline $\mathrm{Cu}^{\mathrm{II}}$ & $\mathrm{Cu}^{\mathrm{I}}$ & Underlying processes \\
\hline $3.5 \mathrm{ps}$ & $7.1 \mathrm{ps}$ & $\mathrm{CT}$ upshift; ${ }^{b} \mathrm{CS}$ rise and upshift \\
\hline $380 \mathrm{ps}$ & $530 \mathrm{ps}$ & CT decay and upshift ${ }^{b}$ CS rise and upshift \\
\hline $6.5 \mathrm{~ns}$ & $8.5 \mathrm{~ns}$ & CT decay; CS upshift and rise; "CS shoulder" ${ }^{\prime c}$ decay \\
\hline $43 \mathrm{~ns}$ & $80 \mathrm{~ns}$ & $\mathrm{CT}$ and CS decay; bleach recovery \\
\hline \multirow[t]{2}{*}{$470-760 \mathrm{~ns}$} & & minor CS decay \\
\hline & $1.6 \mu \mathrm{s}$ & principal RP $(\mathrm{CS})^{d}$ decay; bleach recovery \\
\hline$>50 \mu \mathrm{s}$ & $120 \mu s^{e}$ & decay of residual $\mathrm{CS} ;{ }^{f}$ bleach recovery \\
\hline
\end{tabular}

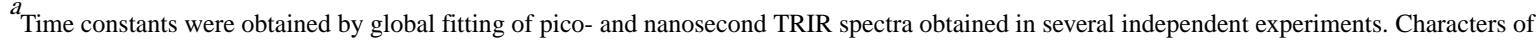
underlying processes were inferred from the decay- and evolution associated spectra (Figures 6,7 ). ${ }^{3} \mathrm{CT}$ relaxation is demonstrated by dynamic shifts of the CT band in TRIR and corresponding evolution associated spectra, and by a derivative-like shape of the decay associated spectra. Convolution of band shifts (relaxation dynamics) and intensity changes (population dynamics) affects the estimated time-constant values.

${ }^{b} \mathrm{CT}$ decay is hard to discern because of simultaneous band shifts and narrowing.

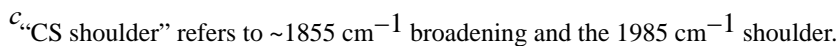

$d_{\text {RP spectral features cannot be distinguished from those of CS (LCS, HCS) }}$

Value taken from low-concentration experiments 21 and fixed in global fits.

$f_{\text {Spectra also show a weak decaying background. }}$ 